\title{
Reversible Beta-Hydrogen Elimination of Three-Coordinate Iron(II) Alkyl Complexes: Mechanistic and Thermodynamic Studies
}

\author{
J avier Vela, ${ }^{\dagger}$ Sridhar Vaddadi, ${ }^{\ddagger}$ Thomas R. Cundari, ${ }^{*, \neq}$ J eremy M. Smith, ${ }^{\dagger, \S}$ \\ Elizabeth A. Gregory, ${ }^{\dagger}$ Rene J . Lachicotte, ${ }^{\dagger}$ Christine J . Flaschenriem, ${ }^{\dagger}$ and \\ Patrick L. Holland*,t \\ Department of Chemistry, University of Rochester, Rochester, New York 12627, and \\ Department of Chemistry, University of N orth Texas, Denton, Texas 76203
}

Received J uly 28, 2004

\begin{abstract}
High-spin organometallic complexes have not received extensive mechanistic study, despite their potential importance as unsaturated intermediates in catalytic transformations. We have found that, with a suitably bulky bidentate ligand, three-coordinate, high-spin alkyl complexes of iron(II) are stable. They undergo isomerization and exchange reactions of the alkyl group through $\beta$-hydride elimination and reinsertion, and the $\beta$-hydride elimination step is rate-limiting. The alkyl complexes transfer a $\beta$-hydrogen atom to $\mathrm{C}=\mathrm{C}, \mathrm{C}=\mathrm{N}$, and $\mathrm{C}=\mathrm{O}$ double bonds and undergo deprotonation by Brønsted acids. The reversible $\beta$-hydride elimination reactions can be used to explore relative $\mathrm{M}-\mathrm{C}$ bond energies. Competition experiments and density functional calculations demonstrate an enthalpic preference for alkyl isomers with iron bound to the terminal carbon of the alkyl fragment. This preference arises from steric and el ectronic effects. The steric preference could be overcome with a phenyl substituent, which steers iron to the benzylic position. A Hammett correlation and density functional calculations suggest that the substituent effect is attributable to resonance stabilization of partial negative charge on the alkyl ligand.
\end{abstract}

\section{Introduction}

Transition metal complexes with a full complement of 18 valence electrons at the metal are the most prevalent in organometallic chemistry. However, it is electronically unsaturated complexes that undergo many of the characteristic and varied reactions of organometallic catalysis. At the forefront of transition metal chemistry, synthetically useful processes including $\alpha$-olefin polymerization, hydrogenation, hydroformylation, and hydroamination have soluble hydrocarbyl complexes of unsaturated metals as key intermediates. Understanding the properties of unsaturated organometallic complexes is therefore crucial in understanding and improving those processes, as well as in devel oping potential applications for novel transformations such as $\mathrm{C}-\mathrm{H}$ and $\mathrm{C}-\mathrm{C}$ bond activation. ${ }^{1,2}$ Hence chemists have synthesized and studied reactive unsaturated organometallic complexes with alkyl ligands. ${ }^{3-5}$

* To whom correspondence should be addressed. E-mail: holland@ chem.rochester.edu.

+ University of Rochester.

₹ University of North Texas.

$\S$ Current address: Department of Chemistry \& Biochemistry, New Mexico State University, Las Cruces, NM 88003.

(1) (a) Collman, J . P.; Hegedus, L. S.; Norton, J . R.; Finke, R. G. Principles and Applications of Organotransition Metal Chemistry; University Science Books: Sausalito, CA, 1987. (b) Spessard, G. O.; Miessler, G. L. Organometallic Chemistry; Prentice Hall: New J ersey, 1997. (c) Crabtree, R. H. The Organometallic Chemistry of the Transition Metals, 2nd ed.; Wiley: New York, 1994; pp 53, 54, and 188-190. (d) Bullock, R. M. I sotope Effects in Reactions of Transition Metal Hydrides. In Transition Metal Hydrides; Dedieu, A., Ed.; VCH: New York, 1991; pp 278-283.
$\beta$-Hydrogen elimination $(\beta$-HE) is a characteristic transformation of these unsaturated alkyl complexes. While isolable, unsaturated early metal alkyl complexes that contain $\beta$-hydrogen atoms are common, el ectronically unsaturated alkyl complexes of the late metals are often unstable toward al kene loss through irreversible $\beta$-HE. In contrast, we recently reported isol able unsaturated alkyliron(II) complexes that cleanly isomerize the

(2) Arakawa, H.; Aresta, M.; Armor, J . N.; Barteau, M. A.; Beckman, E. J .; Bell, A. T.; Bercaw, J . E.; Creutz, C.; Dinjus, E.; Dixon, D. A.; Domen, K.; DuBois, D. L.; Eckert, J .; Fujita, E.; Gibson, D. H.; Goddard, W. A.; Goodman, D. W.; Keller, J .; Kubas, G. J .; Kung, H. H.; Lyons, J. E.; Manzer, L. E.; Marks, T. j.; Morokuma, K.; Nicholas, K. M.; Periana, R.; Que, L.; Rostrup-Nielson, J .; Sachtler, W. M. H.; Schmidt, L. D.; Sen, A.; Somorjai, G. A.; Stair, P. C.; Stults, B. R.; Tumas, W. Chem. Rev. 2001, 101, 953-996.

(3) Representative examples: (a) Wilkinson, G. Angew. Chem. 1974, 86, 664-667. (b) Smith, G. M.; Carpenter, J . D.; Marks, T. J . J . Am. Chem. Soc. 1986, 108, 6805-6807. (c) Hermes, A. R.; Girolami, G. S. Organometallics 1987, 6, 763-768. (d) Richeson, D. S.; Mitchell, J . F.; Theopold, K. H., J . Am. Chem. Soc. 1987, 109, 5868-5670. (e) Romeo, R. Comments Inorg. Chem. 1990, 11, 21-57. (f) Power, P. P. Chemtracts: Inorg. Chem. 1994, 6, 181-195.

(4) (a) Brintzinger, H. H.; Fischer, D.; Muelhaupt, R.; Rieger, B.; Waymouth, R. M. Angew. Chem., Int. Ed. Engl. 1995, 34, 1143-1170. (b) Kersten, J . L.; Kucharczyk, R. R.; Yap, G. P. A.; Rheingold, A. L.; Theopold, K. H. Chem. Eur. J . 1997, 3, 1668-1674. (c) Stahl, S.; Labinger, J . A.; Bercaw, J . E. Angew. Chem., Int. Ed. 1998, 37, 21812192. (d) Beswick, C. L.; Marks, T.J . Organometallics 1999, 18, 24102412. (e) Pariya, C.; Theopold, K. H. Curr. Sci. 2000, 78, 1145-1131.

(5) (a) Urtel, H.; Meier, C.; E Eisentrager, F.; Rominger, F.; J oschek, 1. P.; Hofmann, P. Angew. Chem., Int. Ed. 2001, 40, 781-784. (b) J ohansson, L.; Tilset, M. J . Am. Chem. Soc. 2001, 123, 739-740. (c) MacAdams, L. A.; Kim, W.-K.; Liable-Sands, L. M.; Guzei, I. A.; Rheingold, A. L.; Theopold, K. H. Organometallics 2002, 21, 952-960. (d) Stambuli, J. P.; Buehl, M.; Hartwig, J . F. J . Am. Chem. Soc. 2002 124, 9346-9347. (e) Yamashita, M.; Hartwig, Y. F.J . Am. Chem. Soc. 2004, 126, 5344-5345. (f) Vedernikov, A. N.; Caulton, K. G. Angew. Chem., Int. Ed. 2002, 41, 4102-4104. 


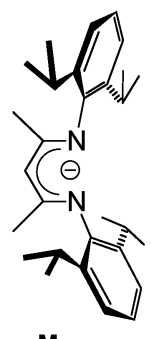

$\mathbf{L}^{\mathrm{Me}}$

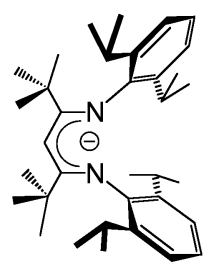

$\mathrm{L}^{\mathrm{tBu}}$
Figure 1. Diketiminate ligands used in this work.

\section{Chart 1}

(a) $\beta$-Hydrogen free compounds

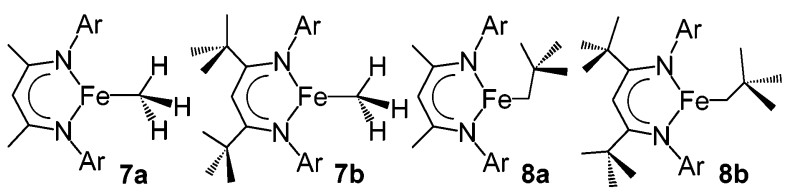

(b) Compounds that contain $\beta$-hydrogen

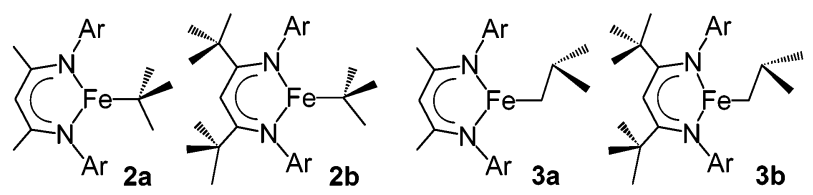<smiles></smiles>

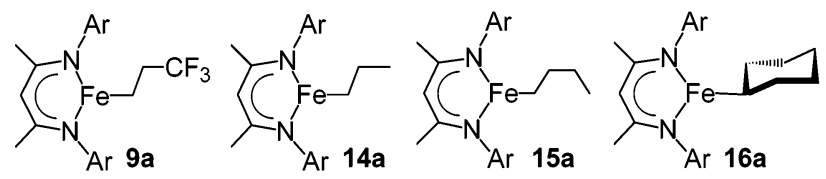

$R=2,6$-di(iso-propyl)phenyl

alkyl group, probably through reversible $\beta$-HE . 6 These complexes contain a monoanionic, bulky diketiminate ligand (Figure 1: L = 2,4-bis(2,6-diisopropylphenylimino)pent-3-yl, LMe, series a; or 2,2,6,6-tetramethyl-3,5bis(2,6-di isopropyl phenylimino)hept-4-yl, L tBu , series b), which maintains $d^{6}$ iron(II) in a three-coordinate geometry with a formal valence electron count of only 12 . In this report, we present full data supporting reversible $\beta$-HE as the alkyl isomerization mechanism, explore the reactions of the transient alkene-hydride intermediate, and use the reversibility of this olefin deinsertion/ insertion chemistry to evaluate metal-carbon bonding preferences in the unsaturated alkyl complexes. We supplement our mechanistic and reactivity studies with DFT calculations.

\section{Results and Discussion}

Synthesis and Isomerization of Alkyl Complexes. As part of our investigations aimed at unveiling the low-coordinate chemistry of the late first-row transition metals, ${ }^{7}$ we isolated paramagnetic, three-coordinate

(6) Vela, J .; Smith, J . M.; Lachicotte, R. J .; Holland, P. L. Chem. Commun. 2002, 2886-2887.

\section{Scheme 1}

(a)

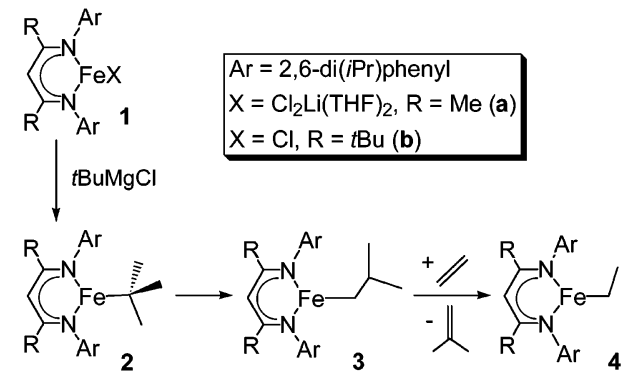

(b)

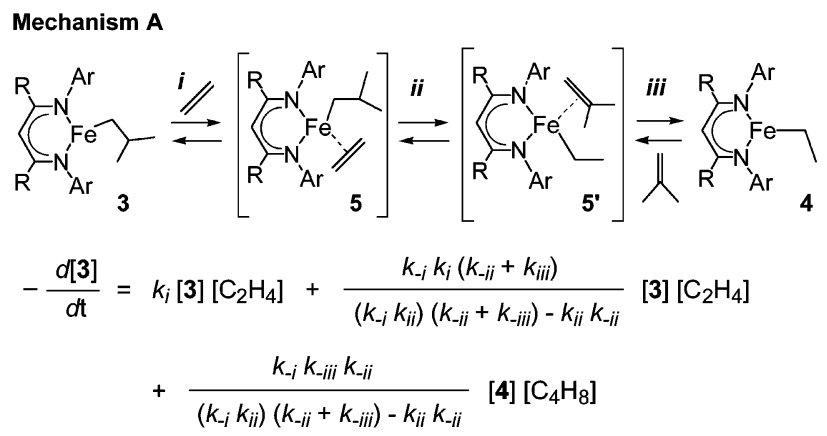

Mechanism B

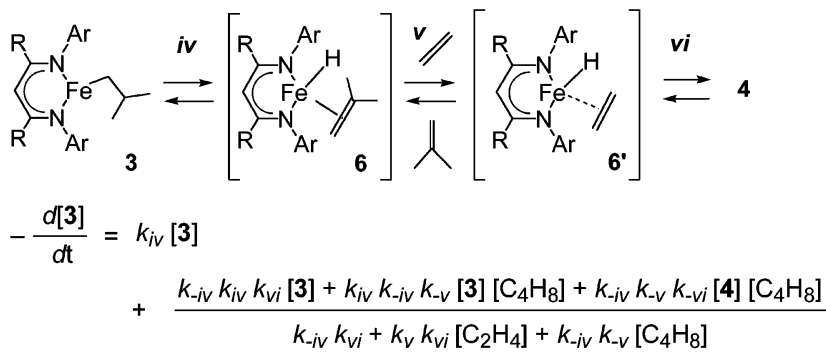

alkyl complexes of iron(II) (Chart 1). The synthesis of some of these compounds has been reported previously. ${ }^{6,8}$ Alkyl complexes were derived from the addition of Grignard or alkyllithium reagents to $\mathrm{L}^{\mathrm{MeF}} \mathrm{e}(\mu-\mathrm{Cl})_{2} \mathrm{Li}$ $(\mathrm{THF})_{2}$ (1a) or L tBuF eCl (1b). ${ }^{7 g}$ For example, the tertbutyl complex LtBuFetBu (2b) was prepared from

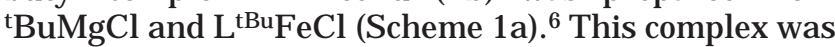
fully characterized and its molecular structure determined by X-ray crystallography. Upon heating, this tertiary complex undergoes complete thermal rearrangement to its isobutyl isomer $L^{\text {tBu}}$ F ei Bu (3b). ${ }^{6}$ When the analogous complex with the smaller ligand $L^{M e}$ was used (Figure 1), the isomerization was too rapid to observe the presumed formation of the tertiary isomer $\mathrm{LMeF}^{\mathrm{MetBu}}$ by ${ }^{1 \mathrm{H}}$ NMR spectroscopy, and the only isolated product was isobutyl complex LMeF eiBu (3a).

(7) (a) Eckert, N. A.; Smith, J . M.; Lachicotte, R. J .; Holland, P. L. Inorg. Chem. 2004, 43, 3306-3321. (b) Vela, J .; Stoian, S.; Flaschenriem, C.; Münck, E.; Holland, P. L. J . Am. Chem. Soc. 2004, 126, 45224523. (c) Eckert, N. A.; Bones, E. M.; Lachicotte, R. J .; Holland, P. L. Inorg. Chem. 2003, 42, 1720-1725. (d) Holland, P. L.; Cundari, T. R.; Perez, L. L.; Eckert, N. A.; Lachicotte, R. J . J . Am. Chem. Soc. 2002, 124, 14416-14424. (e) Andres, H.; Bominaar, E. M.; Smith, J. M.; Eckert, N. A.; Holland, P. L.; Münck, E. J . Am. Chem. Soc. 2002, 124, 3012-3025. (f) Smith, J. M.; Lachicotte, R. J .; Pittard, K. A.; Cundari, T. R.; Lukat-Rodgers, G.; Rodgers, K. R.; Holland, P. L. J . Am. Chem Soc. 2001, 123, 9222-9223. (g) Smith, J. M.; Lachicotte, R. J .; Holland, P. L. Chem Commun. 2001, 1342-1343.

(8) Smith, J. M.; Lachicotte, R. J .; Holland, P. L. Organometallics 2002, 21, 4808-4814. 


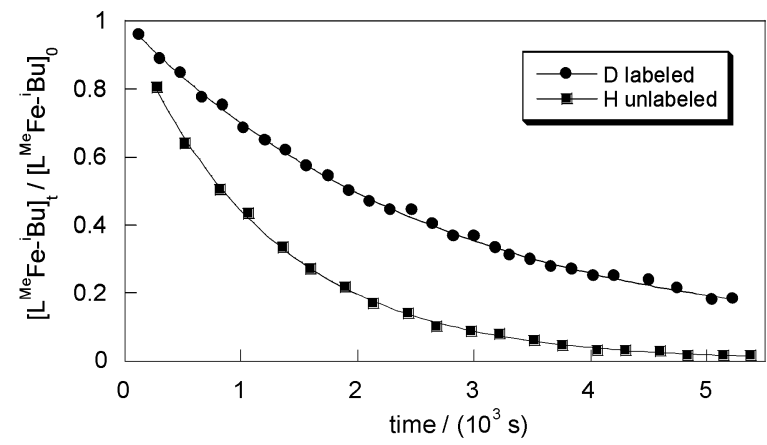

Figure 2. Decay of isobutyl complexes $3 \mathbf{a}\left(\mathrm{C}_{6} \mathrm{D}_{6}, 325 \mathrm{~K}\right)$ in the presence of excess ethylene. $[\mathrm{Fe}]_{\mathrm{T}}=45 \mathrm{mM},\left[\mathrm{C}_{2} \mathrm{H}_{4}\right]_{0}$ $=380 \mathrm{mM}$. Exponential fits to the data are shown.

To test for the intermediacy of al kene-bound species in the isomerization reaction, a solution of isobutyl compound LMeFeiBu was heated to $60{ }^{\circ} \mathrm{C}$ in an NMR tube in the presence of excess (2-19 equiv) ethylene, cleanly giving a solution of ethyl complex L MeFeEt (4a), isobutylene, and the remaining ethylene (Scheme 1a). The alkene exchange reaction from $L^{M e F}$ eiBu to $L^{M e}$ FeEt is reminiscent of chain transfer in $\alpha$-olefin polymerizations catalyzed by late transition metals ${ }^{9}$ including iron, ${ }^{10}$ in which low coordinate active catalysts are thought to be involved.

Mechanism of Alkyl Transfer. Two possible mechanisms have been proposed for chain transfer in alkene polymerization, ${ }^{9}$ and Scheme $1 \mathrm{~b}$ shows these mechanisms in the context of the alkyl exchange of the three coordinate iron complexes. Mechanism A starts with alkene binding (i) to form four-coordinate alkene alkyl intermediate 5, followed by intramolecular hydride transfer (ii) and release of the new alkene (iii). Mechanism $B$ has $\beta$-hydride elimination (iv) to form an alkene hydride intermediate 6 . This intermediate could exchange alkene ( $v$ ) and undergo $\beta$-hydrogen transfer to give a new alkyl complex (vi). All steps are potentially reversible.

Steady-state analysis was used to derive rate laws, because no intermediates are observed. Mechanism A predicts that the rate of consumption of $L^{R} F e i B u$ is dependent on the concentration of ethylene and 2-methyl propene (Scheme 1b). In other words, in mechanism $A$ added alkene is part of the transition state in each el ementary step. In contrast, the same kind of analysis applied to mechanism $B$ yields a rate law in which one of the terms $\left(\mathrm{k}_{\mathrm{iv}}[\mathbf{3}]\right.$, Scheme $\left.1 \mathrm{~b}\right)$ is independent of alkene concentration.

The rate of conversion of isobutyl complex 3a to ethyl complex $\mathbf{4 a}$ is first order in [3a] (Figure 2) and independent of [ethylene]. Exchange of other alkenes having large electronic differences, such as propene or 3,3,3trifluoropropene instead of ethylene, occurred with rate constants similar to that for ethylene (Table 1). Assuming the steady-state approximation above, these observations are inconsistent with mechanism $A$, whose rate

(9) (a) Ittel, S. D.; J ohnson, L. K.; Brookhart, M. Chem. Rev. 2000 100, 1169-1203. (b) Britovsek, G. J . P.; Gibson, V. C.; Wass, D. F. Angew. Chem., Int. Ed. 1999, 38, 428-447.

(10) (a) Britovsek, G. J . P.; Gibson, V. C.; Kimberley, B. S.; Maddox P. J .; McTavish, S. J .; Solan, G. A.; White, A. J . P.; Williams, D. J . Chem. Commun. 1998, 849-850. (b) Small, B. L.; Brookhart, M. Bennett, A. M. A. J . Am. Chem. Soc. 1998, 120, 4049-4050. (c) Small, B. L.; Brookhart, M. J . Am. Chem. Soc. 1998, 120, 7143-7144.

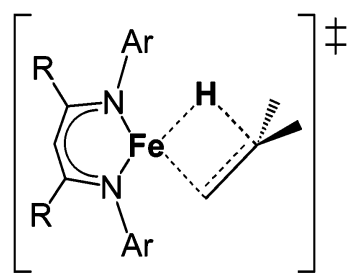

Figure 3. Transition state for step iv (mechanism B, Scheme 1b)

Table 1. Rate Constants for Reaction of LMeF ei Bu (3a) with Alkenes at $336 \mathrm{~K}$ in $\mathrm{C}_{6} \mathrm{D}_{6}$

\begin{tabular}{lccl}
\hline & [Fe] (mM) & [alkene] $(\mathrm{mM})$ & $\mathrm{k}\left(10^{-3} \mathrm{~s}^{-1}\right)$ \\
\hline $\mathrm{CH}_{2}=\mathrm{CH}_{2}$ & 45 & 380 & $1.80 \pm 0.09$ \\
$\mathrm{CH}_{2}=\mathrm{CH}_{2}$ & 45 & 128 & $1.86 \pm 0.02$ \\
$\mathrm{CH}_{2}=\mathrm{CH}_{2}$ & 110 & 840 & $1.83 \pm 0.09$ \\
$\mathrm{CH}_{2}=\mathrm{CH}_{2}$ & 45 & 760 & $1.82 \pm 0.09$ \\
$\mathrm{CH}_{2}=\mathrm{CHCH}_{3}$ & 49 & 211 & $2.1 \pm 0.1$ \\
$\mathrm{CH}_{2}=\mathrm{CHCH}_{3}$ & 49 & 485 & $2.3 \pm 0.1$ \\
$\mathrm{CH}_{2}=\mathrm{CHCH}_{3}$ & 49 & 823 & $2.1 \pm 0.1$ \\
$\mathrm{CH}_{2}=\mathrm{CHCF}_{3}$ & 49 & 319 & $1.61 \pm 0.05$ \\
$\mathrm{CH}_{2}=\mathrm{CHCF}_{3}$ & 49 & 490 & $1.50 \pm 0.06$
\end{tabular}

should al ways depend on alkene concentration. The data are most consistent with mechanism B with iv as the rate-limiting step for isomerization.

An Eyring plot of rate constants for reaction of $\mathbf{3 a}$ with ethylene yiel ded the activation parameters $\Delta \mathrm{H}^{\ddagger}=$ $+18.4 \pm 0.5 \mathrm{kcal} \cdot \mathrm{mol}^{-1}$ and $\Delta \mathrm{S}^{\ddagger}=-17 \pm 2 \mathrm{cal} \cdot \mathrm{mol}^{-1} \cdot \mathrm{K}^{-1}$. The negative entropy of activation is consistent with the transition state for $\beta$ - $\mathrm{HE}$, because motion of the alkyl ligand is restricted in the rate-determining transition state (Figure 3). ${ }^{11,12}$ Positive entropies of activation have been observed in cases where the ratelimiting step is alkene dissociation (v) from an intermediate such as $\mathbf{6} .^{13}$

To gain more insight into the nature of the transition state, alkene exchange was carried out with the deuterated compound L MeF e(iBu- $\left.d_{9}\right)\left(d_{9}-3 a\right)$. Comparison of the rate constants for the reaction of ethyl ene with $3 a$ and $d_{9}$-3a gave a normal deuterium kinetic isotope effect $(\mathrm{KIE})$ of $\mathrm{k}^{\mathrm{H}} / \mathrm{K}^{\mathrm{D}}=2.2 \pm 0.2(325-347 \mathrm{~K})$, Table 2 , I. ${ }^{14}$ Normal kinetic isotope effects of this magnitude are common for $\beta$-H eliminations, ${ }^{1 d, 15}$ for example, $\left(\mathrm{Ph}_{3} \mathrm{P}\right)_{2^{-}}$ (CO)Ir(n-octyl) $\left(\mathrm{k}^{\mathrm{H}} / \mathrm{K}^{\mathrm{D}}=2.28 \pm 0.20\right),{ }_{16}\left(\mathrm{PhMe}_{2} \mathrm{P}\right)_{2}$ (acac)Co-Et $\left(\mathrm{k}^{\mathrm{H}} / \mathrm{k}^{\mathrm{D}}=2.30 \pm 0.05\right),{ }_{17} \mathrm{Cp}^{*}{ }_{2} \mathrm{ScCH}_{2} \mathrm{CHDPh}\left(\mathrm{k}^{\mathrm{H}} /\right.$ $\left.\mathrm{k}^{\mathrm{D}}=2.0 \pm 0.3\right),{ }^{18}(\mathrm{PCP}) \mathrm{RhR}\left(\mathrm{k}^{\mathrm{H}} / \mathrm{K}^{\mathrm{D}}=1.4, \mathrm{PCP}=2,6-\right.$ $\left.\left(\mathrm{CH}_{2} \mathrm{P}-\mathrm{tBu}\right)_{2}\right)_{2} \mathrm{C}_{6} \mathrm{H}_{3}, \mathrm{R}=\mathrm{Et}$ or $\left.\mathrm{nPr}\right) .{ }^{11}$

The isomerization of tert-butyl complex $\mathbf{2} \mathbf{b}$ to isobutyl complex $\mathbf{3 b}$ follows first-order kinetics as well. The activation parameters of $\Delta \mathrm{H}^{\ddagger}=+20 \pm 1 \mathrm{kcal} \cdot \mathrm{mol}^{-1}$ and

(11) Van der Boom, M. E.; Higgitt, C. L.; Milstein, D. Organome tallics 1999, 18, 2411-2419.

(12) Ozawa, F.; Ito, T.; Yamamoto, A. J . Am. Chem. Soc. 1980, 102, 6457-6463.

(13) Romeo, R.; Alibrandi, G.; Scolaro, L. M. Inorg. Chem. 1993, 32, 4688-4694.

(14) An Eyring plot for the temperature dependence of the rate constants of the ethylene exchange data for $3 \mathrm{a}^{\mathrm{D}}$ gives $\Delta \mathrm{H}^{\mathrm{D}}=+18.5$ $\pm 1.2 \mathrm{kcal} / \mathrm{mol}$ and $\Delta \mathrm{S}^{\mathrm{D}}=-18 \pm 2 \mathrm{cal} / \mathrm{mol} \cdot \mathrm{K}$ (see Supporting Information). Unfortunately, the error bars for the activation parameters are large enough to prevent any useful distinction from the unlabeled compound $\mathbf{4 a}$.

(15) A normal KIE of $\mathrm{k}^{\mathrm{H}} / \mathrm{k}^{\mathrm{D}}=4.9 \pm 0.5$ has also been reported for $\beta-\mathrm{H}$ elimination of ethyl groups on an $\mathrm{Fe}(100)$ surface. Burke, M. L. Madix, R. J. J . Am. Chem. Soc. 1991, 111, 3675-3684.

(16) Evans, J .; Schwartz, J .; Urquhart, P. W. J . Organomet. Chem. 1974, 81, C37-C39.

(17) I kariya, T.; Yamamoto, A. J . Organomet. Chem. 1976, 120, 257-284

(18) Burger, B. J .; Thompson, M. E.; Cotter, W. D.; Bercaw, J . E. J . Am. Chem. Soc. 1990, 112, 1366-1377. 
Table 2. Kinetic Isotope Effect of $\beta$-HE Reactions of Butyl Complexes

\begin{tabular}{|c|c|c|c|}
\hline \multicolumn{4}{|c|}{ I. Ethylene Exchange into 3a, $[\mathrm{Fe}]=45 \mathrm{mM}$ in $\mathrm{C}_{6} \mathrm{D}_{6}$} \\
\hline $\mathrm{T}(\mathrm{K})$ & $\mathrm{k}^{\mathrm{H}}\left(10^{-3} \mathrm{~s}^{-1}\right)$ & $k^{D}\left(10^{-3} s^{-1}\right)$ & $k^{H} / k^{D}$ \\
\hline $\begin{array}{l}293 \\
303 \\
312 \\
325 \\
336 \\
347 \\
358\end{array}$ & $\begin{array}{l}0.031 \pm 0.007 \\
0.083 \pm 0.001 \\
0.248 \pm 0.004 \\
0.82 \pm 0.01 \\
1.89 \pm 0.01 \\
4.5 \pm 0.1\end{array}$ & $\begin{array}{l}0.38 \pm 0.01 \\
0.82 \pm 0.02 \\
2.1 \pm 0.2 \\
5.7 \pm 0.7\end{array}$ & $\begin{array}{l}2.16 \pm 0.06 \\
2.3 \pm 0.1 \\
2.1 \pm 0.2\end{array}$ \\
\hline \multicolumn{4}{|c|}{ II. I somerization of $\mathbf{2 b}$ to $\mathbf{3 b}$, [Fe] $=40 \mathrm{mM}$ in $\mathrm{C}_{6} \mathrm{D}_{6}$} \\
\hline $\mathrm{T}(\mathrm{K})$ & $\mathrm{k}^{\mathrm{H}}\left(10^{-3} \mathrm{~s}^{-1}\right)$ & $k^{D}\left(10^{-3} s^{-1}\right)$ & $\mathrm{k}^{\mathrm{H}} / \mathrm{k}^{\mathrm{D}}$ \\
\hline $\begin{array}{l}325 \\
336 \\
347 \\
358 \\
369 \\
380\end{array}$ & $\begin{array}{l}0.129 \pm 0.003 \\
0.54 \pm 0.01 \\
1.50 \pm 0.04 \\
2.9 \pm 0.3\end{array}$ & $\begin{array}{l}0.56 \pm 0.04 \\
1.16 \pm 0.03 \\
3.0 \pm 0.2 \\
5.1 \pm 0.8\end{array}$ & $\begin{array}{l}2.7 \pm 0.2 \\
2.5 \pm 0.3\end{array}$ \\
\hline
\end{tabular}

$\Delta \mathrm{S}^{\ddagger}=-11 \pm 4 \mathrm{cal} \cdot \mathrm{mol}^{-1} \cdot \mathrm{K}^{-1}$ are similar to those for alkene exchange. The reaction rate is independent of the concentration of added isobutylene. Monitoring the rate of isomerization of $\mathrm{L}^{\mathrm{tBuFeC}}\left(\mathrm{CD}_{3}\right)_{3}, \mathrm{~d}_{9}-\mathbf{2} \mathbf{b}$, to $\mathrm{d}_{9}-\mathbf{3} \mathbf{b}$ gave a normal kinetic isotope effect of $\mathrm{k}^{\mathrm{H}} / \mathrm{K}^{\mathrm{D}}=2.6 \pm$ 0.2 (347-358 K, Table 2, II). The similar kinetic isotope effects, along with the lack of dependence on alkene concentration and similar activation parameters, strongly indicate that the isomerization and al kyl transfer reactions share a common rate-determining step, in which a $\mathrm{C}-\mathrm{H}$ bond of the alkyl ligand is cleaved. The most reasonable such step is $\beta$-hydride elimination to give an alkene hydride intermediate, because this intramolecular reaction does not consume or produce free alkene. The slower rates with the bulkier ligand $L^{\mathrm{tBu}}$ compared to $\mathrm{L}^{\mathrm{Me}}$ are consistent with an increase in coordination number at iron in the transition state of $\beta$-HE (Figure 3). Compounds 7a ( $\mathrm{R}=$ methyl) and $\mathbf{8 a}$ ( $R=$ neo-pentyl) do not react with excess ethylene or 1-hexene for days at $120{ }^{\circ} \mathrm{C}$, due to their lack of $\beta$-hydrogen atoms.

Nature of the Alkene Exchange Step. Because hydride intermediate $\mathbf{6}$ lies after the rate-determining step, kinetics studies do not distinguish whether alkene exchange ( $v$ in Scheme $1 b$ ) is associative (A) or dissociative(D). To distinguish these possibilities, we performed a crossover experiment using two different diketiminate ligands ( $\mathrm{L}^{\mathrm{Me}}$ and $\mathrm{L}^{\mathrm{tBu}}$ ) and two different alkyl ligands (isobutyl and ethyl). Assuming that $\beta$ - $\mathrm{H}$ elimination is the only pathway for crossover, we hypothesized that scrambling of labels would occur only if alkene dissociation occurred in at least one of the two compounds ( $D$ pathway of alkene exchange). A lack of scrambling would indicate that a free alkene never forms in solution (i.e., both complexes follow an A pathway). Heating (60 ${ }^{\circ} \mathrm{C}$ overnight) a solution of $L^{M e} \mathrm{~F}$ eiBu (3a) and $\mathrm{L}^{\mathrm{tBu}} \mathrm{F}$ eEt

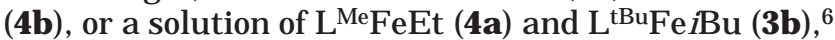
produced a mixture at equilibrium containing all four compounds. This suggests that al kene exchange occurs through a dissociative mechanism. ${ }^{6}$

However, further control experiments with compounds that do not contain $\beta$-hydrogens question the validity of conclusions from crossover experiments. Scrambling does not occur between neo-pentyl ( $L^{R}$ $\mathrm{FeCH}{ }_{2} \mathrm{tBu}$ ) and methyl ( $\mathrm{L}^{\prime} \mathrm{FeMe}$ ) compounds of different diketiminate ligands, but complex LMeFeMe (7a) does react with isobutyl complex $\mathbf{3} \mathbf{b}$ to form a mixture of $\mathbf{7 a}, \mathbf{7 b}, \mathbf{3 b}$, and $\mathbf{3 a}$. Because some compounds with and without $\beta$-H react to scramble alkyl groups, there is some pathway for exchange that does not require $\beta$-HE. As a result, it is not possible from the crossover experiments to definitively distinguish between associative and dissociative mechanistic possibilities for al kene exchange. This conclusion, based on additional experiments, differs from that proposed in the preliminary communication. 6,19

In the absence of experimental data to distinguish A from $D$ olefin exchange, calculations were carried out to probe the nature of the olefin exchange step. The crucial issue in comparing the associative and dissociative pathways involves the energetic accessibility of the putative five-coordinate $\left[\mathrm{LFe}(\mathrm{H})(\text { olefin })_{2}\right]$ and threecoordinate [LFeH] intermediates. The energy of threecoordinate [ $\mathrm{L}^{\prime} \mathrm{FeH}$ ] (where $\mathrm{L}^{\prime}$ is the truncated diketiminate $\mathrm{N}_{2} \mathrm{C}_{3} \mathrm{H}_{5}{ }^{-20}$ was minimized at the B $3 L Y P / 6-31 \mathrm{G}(\mathrm{d})$ level of theory, giving an $\mathrm{Fe}-\mathrm{H}$ bond distance of 1.66 $\AA$. Adding ethylene gave a binding enthal py of only 7.8 $\mathrm{kcal} / \mathrm{mol}$ for the first ethylene. Because the activation barrier for a $D$ mechanism is primarily the loss of ol efin from 6, this weak binding energy suggests that such a mechanism could take place rapidly. Despite investigation of several conformations, no stable bis(olefin) complex [ $\left.\mathrm{L}^{\prime} \mathrm{Fe}(\mathrm{H})\left(\mathrm{C}_{2} \mathrm{H}_{4}\right)_{2}\right]$ was found as an energy minimum, and the second ethylene dissociated upon geometry optimization. The intermediacy of a bis(olefin)hydride complex is even less plausible for the more sterically congested experimental ligand systems. Therefore, the calculations argue against an associative pathway and favor a dissociative pathway for the ol efin exchange step. We have synthesized a diketiminatesupported iron hydride, ${ }^{21}$ and preliminary experiments confirm that it inserts alkenes as postulated in the dissociative mechanism for alkene exchange.

Generality of the Hydride Transfer Reaction. We were interested that $\mathrm{L}^{\mathrm{Me}} \mathrm{FeCH}{ }_{2} \mathrm{CH}\left(\mathrm{CH}_{3}\right)_{2}$ (3a), a 12electron late-metal alkyl containing $\beta$-hydrogens, underwent alkyl transfer to ethylene to form the ethyl complex $\mathrm{L}^{\mathrm{MeFeCH}} \mathrm{CH}_{2} \mathrm{CH}_{3}$ (4a) (complete by $\mathrm{NMR}$, 85\% isolated yield). ${ }^{6}$ To investigate the synthetic utility of this reaction, 3a was heated to $60{ }^{\circ} \mathrm{C}$ with a stoichiometric amount of different alkenes in toluene overnight. Using 3,3,3-trifluoropropene instead of ethylene leads to formation of $\mathrm{L}^{\mathrm{MeFeCH}} \mathrm{CH}_{2} \mathrm{CF}_{3}(9 \mathrm{a})$, whereas the reaction of 3a with styrene yields $\mathrm{L}^{\mathrm{MeFeCH}}\left(\mathrm{CH}_{3}\right) \mathrm{Ph}$ (10a). Both $9 \mathbf{a}$ and $10 a$ were isolated in good yiel ds (up to $80 \%$ ), and their connectivity was confirmed by X-ray crystallography (Figure 4). Interestingly, the $\alpha$ carbon in complex $\mathrm{L}^{\mathrm{MeFeCH}}\left(\mathrm{CH}_{3}\right) \mathrm{Ph}(\mathbf{1 0 a})$ is stereogenic, making the two halves of the diketiminate ligand chemically and magnetically inequivalent. This is evident in the ${ }^{1} \mathrm{H}$ NMR spectrum: each of the isopropyl $\mathrm{CH}$ and $\mathrm{CH}_{3}$

(19) The mechanism through which direct alkyl exchange can occur is unclear at this time, but may proceed through alkyl-for-hydride exchange with unobserved hydride complexes formed from $\beta$-hydrogencontaining alkyl complexes. In support of this idea, thermolysis of $\mathrm{L}^{\mathrm{Me}}$ $\mathrm{FeCH}_{3}$ (7a) with [ $\left.\mathrm{L}^{\mathrm{tBu}} \mathrm{FeH}\right]_{2}{ }^{21}$ gave a mixture containing $\mathbf{7 b}$.

(20) We have used models of this type successfully to understand the electronic structure and geometries of the methyl complexes $\mathrm{LtBu}_{\mathrm{B}}$ $\mathrm{MCH}_{3}{ }^{\mathrm{Tb}}(\mathrm{M}=\mathrm{Fe}, \mathrm{Co})$ and bridging dinitrogen complexes [ $\mathrm{L}^{\mathrm{HBu}}$ FeNNFeL tBu $]^{n}(\mathrm{n}=0,2-)^{7 f}$

(21) Spectroscopic and kinetic evidence support the presence of the three-coordinate iron(II) hydride complex L tBuFeH: Smith, J. M.; Lachicotte, R. J .; Holland, P. L. J . Am. Chem. Soc. 2003, 125, 1375213753. 


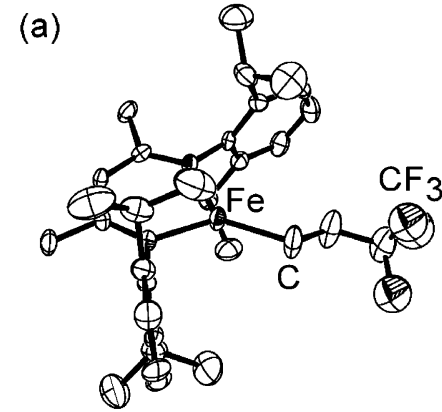

(c)

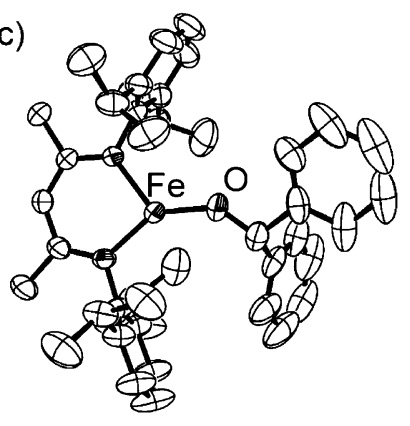

(e)

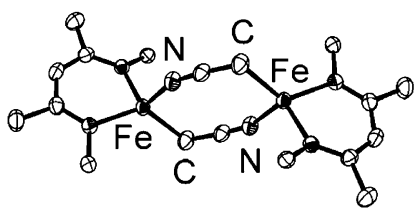

(b)
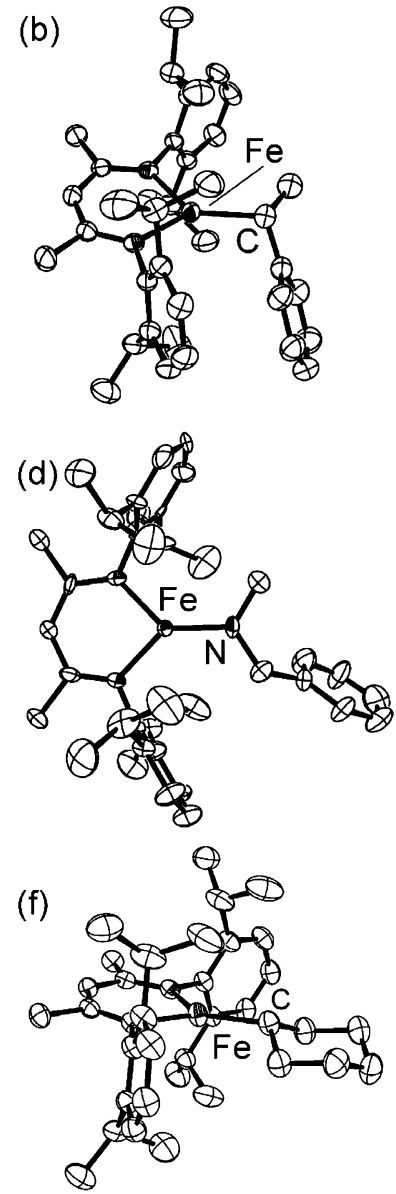

Figure 4. Molecular structures of (a) $\mathrm{LMeFeCH}_{2} \mathrm{CH}_{2} \mathrm{CF}_{3}$ (9a), (b) LMeF eCH $\left(\mathrm{CH}_{3}\right) \mathrm{Ph}$ (10a), (c) L MeF eOCHPh (d) LMeFeN $\left(\mathrm{CH}_{3}\right)\left(\mathrm{CH}_{2} \mathrm{Ph}\right)$ (12), (e) $\left[\mathrm{LMeFe}\left(u-\mathrm{CH}_{2} \mathrm{CN}\right)\right]_{2}$ (13), and (f) LMeF eCy (16a). Thermal ellipsoids are shown at 50\% probability. Hydrogen atoms (and aryl groups in 13) have been omitted for clarity.

signals from the ligand splits into two different signals (Scheme 2, see further discussion below).

We then explored the extension of the alkyl transfer reaction to heteroatom-substituted analogues of an ol efin. ${ }^{22}$ Reacting 3a with 1 molar equiv of benzophenone in hot toluene gives $\mathrm{LMeFeOCHPh}_{2}$ (11), the product of hydride transfer to the ketone (Scheme 3a). Similarly, the stoichiometric reaction of $3 a$ with $(\mathrm{N}$ methyl)benzophenone imine, $\mathrm{PhCHNMe}$, gave the amido complex LMeFeN $\left(\mathrm{CH}_{3}\right)\left(\mathrm{CH}_{2} \mathrm{Ph}\right)$ (12, Scheme $\left.3 b\right)$. Compl exes $\mathbf{1 1}$ and $\mathbf{1 2}$ were fully characterized and their structures confirmed by X-ray diffraction (Figure 4). 2-M ethyl propene is the only non-iron byproduct detected by ${ }^{1} \mathrm{H}$ NMR in the reactions between the hydrocarbyls such as $3 a$ with ol efins, a ketone, or an imine. Therefore, the alkyl complexes can react as their unobserved alkene hydride isomer, to add $\mathrm{Fe}-\mathrm{H}$ across a $\mathrm{C}-\mathrm{C}$, $\mathrm{C}-\mathrm{N}$, or $\mathrm{C}-\mathrm{O}$ double bond.

Alkyl Complexes Can Act as Brønsted Bases. The three-coordinateiron(II) alkyls also engage in acid-base

(22) (a) Abdur-Rashid, K.; Clapham, S. E.; Hadzovic, A.; Harvey, J . N.; Lough, A. J .; Morris, R. H. J . Am. Chem. Soc. 2002, 124, 1310413118. (b) Emslie, D. J . H.; Piers, W. E.; Parvez, M.; McDonald, R. Organometallics 2002, 21, 4226-4240. (c) Liang, F.; J acobsen, H.; Schmalle, H. W.; F ox, T.; Berke, H. Organometallics 2000, 19, 19501962. (d) Lin, Z.; Marks, T. J . J . Am. Chem. Soc. 1990, 112, 55135525. (e) J ordan, R. F.; Bajgur, C. S.; Dasher, W. E.; Rheingold, A. L. Organometallics 1987, 6, 1041-1051.

Scheme 2
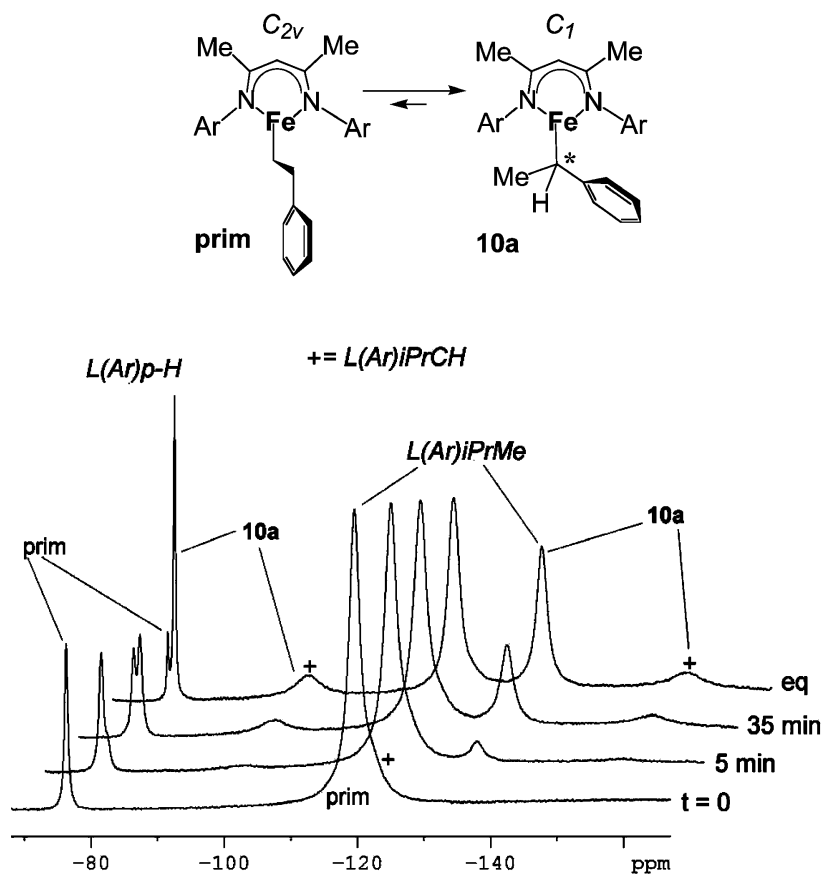

Scheme 3

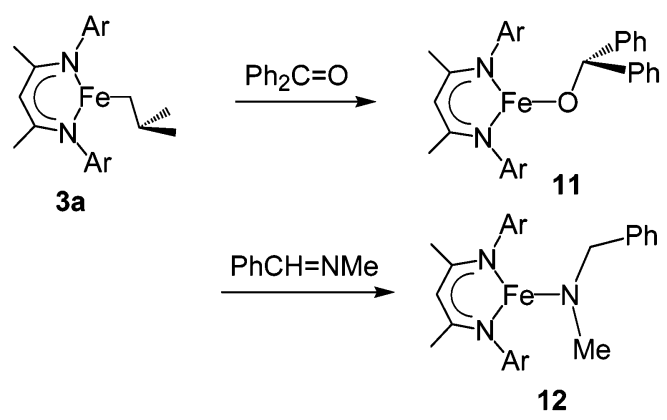

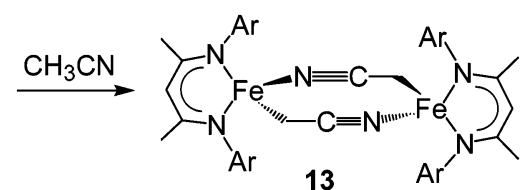

reactions. For instance, compound $\mathbf{8 a}$ reacts quantitatively with 1 molar equiv of 2,6-diisopropylaniline, and the only iron-containing product is $\mathrm{L}^{\mathrm{MeF}} \mathrm{eNH}$ (2,6-diisopropylphenyl) (12); ${ }^{7 a} \mathrm{C}_{5} \mathrm{H}_{12}$ was detected by GC/MS. Similarly, all alkyl complexes $\mathrm{L}$ MeF eR react with acetonitrile to form compound $\mathbf{1 3}$ (Scheme 3c). X-ray crystallography showed that $\mathbf{1 3}$ is a dimer in which two [L MeFe] fragments are linked by two deprotonated acetonitrile ligands (Figure 4). The byproduct was alkane when $R$ did not have $\beta$-hydrogens. Alkene was detected (GC/MS) when the original alkyl complex had $\beta$-hydrogens, suggesting that the hydride may be a more kinetically accessible base.

Linear versus Branched Three-Coordinate Iron(II) Alkyls. With understanding of the general mechanistic features and the scope of the reactions of the iron(II) alkyls, we set about learning thermodynamics from the relative stabilities of the different alkyl complexes. We mentioned that the tert-butyl complexes $L^{R_{-}}$ $\mathrm{Fe}^{\mathrm{t}} \mathrm{Bu}\left(\mathbf{2} \mathbf{a}\right.$, and isolable $\mathbf{2}^{6}{ }^{6}$ ) quantitatively rearrange to their corresponding primary isomers $L^{R} F$ eiBu ( $3 a$ and 3b). Similarly, the reactions of $\mathrm{L}^{\mathrm{MeF}} \mathrm{e}(\mu-\mathrm{Cl})_{2} \mathrm{Li}(\mathrm{THF})_{2}$ 
with isopropylmagnesium chloride (through direct metathesis) and of L MeFeiBu (3a) with 3,3,3-trifluoropropene (through al kyl transfer) yield the linear products $\mathrm{L}^{\mathrm{MeFeC}} \mathrm{CH}_{2} \mathrm{CH}_{2} \mathrm{CH}_{3}$ (14a) ${ }^{23}$ and L ${ }^{\mathrm{MeFeCH}} \mathrm{CH}_{2} \mathrm{CH}_{2} \mathrm{CF}_{3}$ (9a), respectively. In an attempt to increase the ratio of secondary to primary positions, we also prepared the compound LMeF e ${ }^{n} B u(15 a)$. Neither $\mathbf{9 a}, \mathbf{1 4 a}$, nor 15a undergoes rearrangement to its branched isomer upon prolonged heating $\left(110{ }^{\circ} \mathrm{C}, 5\right.$ days), as observed by ${ }^{1} \mathrm{H}$ NMR. Therefore, among $C_{4}$ and $C_{3}$ hydrocarbyl complexes, the thermally stable isomers are the compounds with the primary carbon bound to iron (formally, the 1,2-insertion products). The isomerization equilibria in these reactions therefore lie toward the linear isomer with an equilibrium constant of at least $\mathrm{K}_{\mathrm{eq}}>100 \mathrm{n} /$ iso or iso/tert ratio), ${ }^{24}$ implying that for these transformations the free energy, $\Delta \mathrm{G}^{\circ}$, is more negative than $-2.7 \mathrm{kcal} / \mathrm{mol}$.

The branched complex $\mathrm{L}^{\mathrm{MeFeCH}}\left(\mathrm{CH}_{3}\right) \mathrm{Ph}$ (10a), formally a 2,1-insertion product formed from the alkyl transfer reaction between $\mathrm{L}^{\mathrm{MeF}} \mathrm{FeiBu}(\mathbf{3 a})$ and styrene, stands in contrast with the observed preference for linear chains in all the other alkyl complexes. Formation of $10 \mathrm{a}$ occurs regardless of the synthetic route employed, as reacting $\mathrm{L}$ MeFe $(\mu-\mathrm{Cl})_{2} \mathrm{Li}(\mathrm{THF})_{2}$ with $\mathrm{PhCH}_{2} \mathrm{CH}_{2} \mathrm{MgCl}$ in ether at room temperature overnight gave the same branched product. Nonetheless, a closer look at the ${ }^{1} \mathrm{H}$ NMR spectrum of 10a revealed one minor set of signals that remained after several recrystallizations. To investigate this phenomenon, we used ${ }^{1} \mathrm{H}$ NMR spectroscopy to monitor the synthesis of $10 a$ from $\left[\mathrm{LMeF} \mathrm{eCl}_{2}\right.$ and $\left(\mathrm{PhCH}_{2} \mathrm{CH}_{2}\right)_{2} \mathrm{Mg}$ in toluene- $\mathrm{d}_{8}$. The mysterious set of signals appears immediately upon mixing the organomagnesium and iron chloride precursors, before proceeding to the equilibrium mixture. The initial pattern consists of 10 signals, typical of a $\mathrm{C}_{2 v}$ symmetry molecule (Scheme 2). ${ }^{25}$ Ther efore, we assign these resonances to the primary complex $\mathrm{L}$ MeFeCH${ }_{2} \mathrm{CH}_{2} \mathrm{Ph}$ (prim), the kinetic product of the metathesis reaction.

Integration of peaks from ${ }^{1} \mathrm{H}$ NMR spectra shows that the equilibrium ratio of prim to 10 a is about 1:9 at 25 ${ }^{\circ} \mathrm{C}$, but this ratio decreases with temperature. The relation between equilibrium constants and temperature was fit to a van't Hoff plot (see Supporting Information), giving $\Delta \mathrm{H}^{\circ}=-2.8 \pm 0.1 \mathrm{kcal} \cdot \mathrm{mol}^{-1}$ and $\Delta \mathrm{S}^{\circ}=-4.9 \pm 0.3 \mathrm{cal} \cdot \mathrm{mol}^{-1} \cdot \mathrm{K}^{-1}$. The negative value of $\Delta \mathrm{S}^{\circ}$ shows that the reaction is entropically unfavorable, most likely because the branched benzylic product (10a) is more vibrationally restricted from steric effects. The entropic effect is overcome by the larger and favorable enthalpic contribution.

It is tempting to ascribe this enthal pic change to the fact that the benzylic $\mathrm{C}-\mathrm{H}$ bond in ethylbenzene $(\sim 85$ $\mathrm{kcal} / \mathrm{mol}$ ) is substantially weaker than a primary $\mathrm{C}-\mathrm{H}$

(23) We have reported that using the larger diketiminate $L^{\text {tBu }}$ gives isolable $\mathrm{L}^{\mathrm{tB} u F}$ etB $\mathrm{u}^{6}$ and $\mathrm{L}^{\mathrm{tB} u F}$ eiPr. ${ }^{8}$ These complexes rearrange to their linear isomers on extended heating.

(24) Calculation based on ${ }^{1} \mathrm{H}$ NMR detection limit of $1 \%$. Ebsworth, E. A. V.; Rankin, D. W. H.; Cradock, S. Structural Methods in Inorganic Chemistry, 2nd ed.; CRC Press: Boca Raton, FL, 1991; pp 1-114.

(25) Two different isopropyl- $\mathrm{CH}_{3}$ signals are seen for $\mathrm{C}_{2 v}$ symmetric iron(II) diketiminate complexes because steric bulk prevents free rotation of the $\mathrm{C}(\operatorname{aryl})-\mathrm{N}$ bond. See: Panda, A.; Stender, M.; Wright R. J .; Olmstead, M. M.; Klavins, P.; Power, P. P. Inorg. Chem. 2002, $41,3909-3916$. The $\alpha$ and $\beta$ protons in the phenethyl group are not visible by ${ }^{1} \mathrm{H}$ NMR, as is typical for paramagnetic iron(II) alkyl complexes. bond $(\sim 100.5 \mathrm{kcal} / \mathrm{mol}) .{ }^{26}$ However, metal-carbon bonds are known to become disproportionately strong as the correspondinghydrogen-carbonbondstrengthincreases, ${ }^{27-29}$ which makes the preference of iron for benzylic positions surprising. To investigate this feature further, we generated a series of phenethyl/ $\alpha$-methylbenzyl complexes bearing electron-donating groups in the para position, by treating L MeFeCy (16a) with a stoichiometric amount of the substituted styrene. Each reaction proceeded smoothly to give a mixture of primary and benzylic products. In all cases, 16a was completely consumed, as evidenced by ${ }^{1} \mathrm{H}$ NMR spectroscopy.

The equilibrium constants $\left(\mathrm{K}_{\text {eq }}\right)$ for the $\mathrm{p}-\mathrm{Me}$-, OMe, and-NMez-substituted benzyl/phenethyl systems were measured at different temperatures by ${ }^{1} \mathrm{H}$ NMR spectroscopy. The ratio of benzylic to primary isomer decreases with greater electron-donating ability of the substituent (see Supporting Information). 30 At room temperature $(298 \mathrm{~K})$, the population of primary isomer changes in the order $6 \%(\mathrm{H}), 11 \%$ (p-Me), 18\% (p-OMe), $20 \%\left(p-\mathrm{NMe}_{2}\right)$. There is a relationship between the logarithm of the equilibrium ratio of isomers and the Hammett constants $\sigma_{\mathrm{p}},{ }^{31} \sigma^{+, 31}$ and $\sigma_{\mathrm{p}}(\omega)^{32}$ (the linear correlation coefficients at $333 \mathrm{~K}$ were $0.929,0.939$, and 0.971 , respectively). A plot of In $K_{\text {eq }}$ vs $\sigma_{\mathrm{p}}(\omega)$ is shown in Figure $5 .{ }^{33}$ The positiveslope of $1.2-1.3$ indicates that there is a slightly greater preference for the benzylic isomer when less electron-donating groups are present on the aryl ring.

(26) (a) Blanksby, S. J .; Ellison, G. B. Acc. Chem. Res. 2003, 36, 255-263. (b) Brocks, J. J .; Beckhaus, H.-D.; Beckwith, A. L. J .; Rüchardt, C. J . Org. Chem. 1998, 63, 1935-1943. (c) Tsang, W. In Energetics of Organic Free Radicals; Martinho Simões, J. A., Greenberg, A., Liebman, F., Eds.; Blackie Academic and Professional: London, 1996; pp 22-58. (d) McMillen, D. F.; Golden, D. M. Annu. Rev. Phys. Chem. 1982, 33, 493. (c) Kerr, J. A. In CRC Handbook of Chemistry and Physics, 71st ed.; Lide, R. L., Ed.; CRC Press: Boca Raton, FL, 1990; pp 9_86-9 98.

(27) (a) Halpern, J. Acc. Chem. Res. 1982, 13, 238-244. (b) Bruno, J. W.; Marks, T. J .; Morss, L. R. J . Am. Chem. Soc. 1983, 105, 68246832. (c) Stoutland, P. O.; Bergman, R. G.; Nolan, S. P.; Hoff, C. D. Polyhedron 1988, 7, 1429-1440. (d) Schock, L. E.; Marks, T.J . J . Am Chem. Soc. 1988, 110, 7701-7713. (e) Marks, T. J .; Gagne, M. R.; Nolan, S. P.; Schock, L. E.; Seyam, A. M.; Stern, D. Pure Appl. Chem. 1989, 61, 1665-1672. (f) Nolan, S. P.; Stern, D.; Marks, T. J . J . Am. Chem. Soc. 1989, 111, 7844-7853.

(28) (a) Halpern, J. ACS Symp Ser, 1990, 428, 100-112. (b) Martinho Simões, J. A.; Beauchamp, J . L. Chem. Rev. 1990, 90, 629688. (c) Drago, R. S.; Wong, N. M.; Ferris, D. C. J . Am. Chem. Soc 1992, 114, 91-98. (d) Hoff, C. D. Prog. Inorg. Chem. 1992, 40, 503561. (e) Diogo, H. P.; Simoni, J . A.; Minas da Piedade, M. E.; Dias, A R.; Martinho Simões, J. A. J. Am. Chem. Soc. 1993, 113, 2764-2774. (f) Freiser, B. S. Acc. Chem. Res. 1994, 27, 353-360. (g) Martinho Simões, J. A.; Minas da Piedade, M. E. In Energetics of Organic Free Radicals; Martinho Simões, J. A., Greenberg, A., Liebman, F., Eds. Blackie Academic and Professional: London, 1996; pp 169-195.

(29) (a) Clot, E.; Besora, M.; Maseras, F.; Mégret, C.; Eisenstein, O.; Oelckers, B.; Perutz, R. N. Chem. Commun. 2003, 490-491. (b) Li, G.; Zhang, F. F.; Pi, N.; Chen, H. L.; Zhang, S. Y.; Chan, K. S. Chem. Lett. 2001, 30, 284-285. (c) Wick, D. D.; jones, W. D. Organometallics 1999, 18, 495-505. (d) Bennett, J. L.; Wolczanski, P. T. J . Am. Chem. Soc. 1997, 119, 10696-10719. (e) Holland, P. L. Andersen, R. A.; Bergman, R. G.; Huang, J .; Nolan, S. P. J . Am. Chem. Soc. 1997, 119, 12800-12814.

(30) Due to the small change in equilibrium ratios with varying substitution, the $\Delta \mathrm{H}^{\circ}$ values derived from van't $\mathrm{H}$ off plots are too similar to allow comparison on this basis.

(31) (a) Hansch, C.; Leo, A.; Taft, R. W. Chem. Rev. 1991, 91, 165195. (b) Smith, M. B.; March, J . Advanced Organic Chemistry, 5th ed.; Wiley: New York, 2001; pp 368-375.

(32) Recent calculations provide Hammett constants corrected for solvent effects: Domingo, L. R.; Perez, P.; Contreras, R. J . Org. Chem. 2003, 68, 6060-6062.

(33) A plot using $\sigma^{-}$showed a poor correlation. Phenethyl groups with more electron-withdrawing substituents had an undetectably small amount of the terminal isomer. 

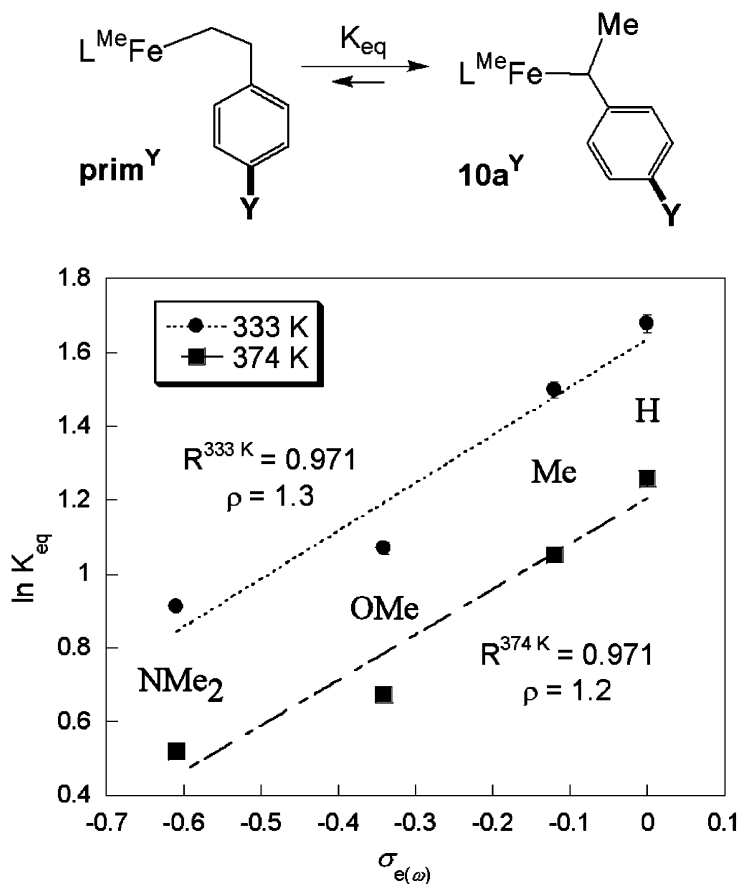

Figure 5. Hammett plot for the isomerization equilibria between para-substituted phenethyl and $\alpha$-(methyl)benzyl complexes in $\mathrm{C}_{6} \mathrm{D}_{6}, 333-373 \mathrm{~K}$, $[\mathrm{Fe}]_{\mathrm{T}}=63 \mathrm{mM}$.

Computations on the Stability of Three-Coordinate I ron(II) Alkyls. To obtain more information on the relative stability of the diketiminate iron(II) alkyl complexes, density functional calculations were performed at the B $3 \mathrm{LYP}$ level, using either the truncated diketiminate $\mathrm{C}_{3} \mathrm{~N}_{2} \mathrm{H}_{5}{ }^{-}\left(\mathrm{L}^{\prime}\right)^{20}$ or the full ligand $\mathrm{L}^{\mathrm{Me}}$. The calculated energies were converted to enthalpies by applying zero-point energy and finite temperature corrections calculated from $B 3 L Y P / 6-31 G(d)$ vibrational frequencies. ${ }^{34}$

B3LYP/6-31G(d) optimization of the lowest energy conformers obtained from a molecular mechanics-based conformational searching of LMeFeiPr and LMeFenPr shows that $\mathrm{H}(\mathrm{nPr})<\mathrm{H}(\mathrm{iPr})$ by $3.2 \mathrm{kcal} / \mathrm{mol}$. This agrees with a lower limit of $2.7 \mathrm{kcal} / \mathrm{mol}$ based on the detection limit of ${ }^{1} \mathrm{H}$ NMR spectroscopy (see above). ${ }^{24}$ Using a similar strategy, $\mathrm{L}^{\mathrm{Me}} \mathrm{FeCH} \mathrm{CH}_{2} \mathrm{CH}_{2} \mathrm{Ph}$ was calculated to be $3.1 \mathrm{kcal} / \mathrm{mol}$ higher in energy than $\mathrm{L} M e \mathrm{FeCH}\left(\mathrm{CH}_{3}\right) \mathrm{Ph}$, in agreement with the observed reaction enthal py of 2.8 $\pm 0.1 \mathrm{kcal} / \mathrm{mol}$. The high accuracy of the $\mathrm{QM} / \mathrm{MM}$ results suggest that the DFT methodology is fundamentally sound for these systems.

Calculations using the truncated $\mathrm{L}^{\prime}$ ligand gave poorer agreement $(\Delta \mathrm{H}=2.1$ and $7.1 \mathrm{kcal} / \mathrm{mol}$ for the two reactions, respectively). In each case, the secondary isomer is cal culated to be unreasonably stable, strongly suggesting that steric effects are important in determining the energies of the experimental compounds. More extensive calculations were carried out on the truncated $L^{\prime}$ models for two reasons: computational expediency, and because we were more interested in the inherent (not influenced by the steric clash of the diketiminate and the alkyl ligands) enthalpic contributions to the iron-carbon bonds.

(34) Hehre, W. J .; Radom, L.; Schleyer, P. v. R.; Pople, J . A. Ab Initio Molecular Orbital Theory; Wiley: New York, 1986.
Table 3. Calculated (B3L YP/6-31G(d)) Thermodynamic Parameters for L'FeR; Energies in $\mathrm{kcal} / \mathrm{mol}$

\begin{tabular}{|c|c|c|c|c|}
\hline $\mathrm{R}$ & $D(H R)^{a}$ & $\Delta \mathrm{H}^{\mathrm{b}}$ & $\mathrm{D}(\mathrm{Fe}-\mathrm{R})-\mathrm{D}(\mathrm{Fe}-\mathrm{H})$ & $\Delta \mathrm{H}_{\beta-\mathrm{HE}^{\mathrm{C}}}$ \\
\hline $\begin{array}{l}\mathrm{H} \\
\mathrm{Me}\end{array}$ & 104.2 & $\begin{array}{l}0.0 \\
7.6\end{array}$ & $\begin{array}{r}0.0 \\
-6.8\end{array}$ & \\
\hline $\mathrm{Et}$ & 101.1 & 11.3 & -14.4 & 21.8 \\
\hline $\mathrm{nPr}$ & 101.0 & 9.5 & -12.7 & 20.4 \\
\hline $\mathrm{iPr}$ & 98.6 & 11.6 & -17.2 & 17.8 \\
\hline $\mathrm{iBu}$ & 101.0 & 11.5 & -14.7 & 16.1 \\
\hline tBu & 96.5 & 15.2 & -22.9 & 13.9 \\
\hline $\mathrm{PhCH}_{2} \mathrm{CH}_{2}$ & 100.5 & 12.0 & -15.7 & 16.0 \\
\hline $\mathrm{PhCHMe}$ & 84.7 & 4.9 & -24.4 & 23.0 \\
\hline
\end{tabular}

a HR bond energies from NIST, except $R=$ phenethyl, which was calculated (see text). ${ }^{b}$ Calculated enthal py for reaction in eq 1. ${ }^{\mathrm{C}}$ Calculated enthalpy for $\beta$-hydride elimination.

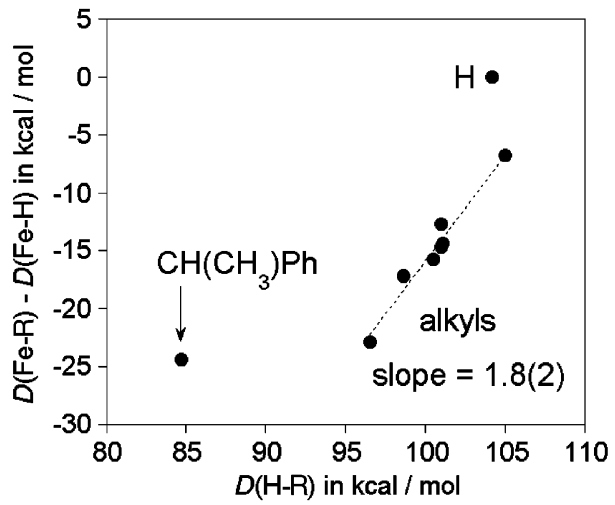

Figure 6. Plot of calculated $D(F e-R)$ vs $D(H-R)$ for $L^{\prime} F e R$ compounds $\left(\mathrm{L}^{\prime}=\mathrm{N}_{2} \mathrm{C}_{3} \mathrm{H}_{5}{ }^{-}\right.$).

The calculated energies of iron alkyl compounds give relative bond energies through the conceptual reaction

$$
\mathrm{L}^{\prime} \mathrm{FeH}+\mathrm{HR} \rightarrow \mathrm{L}^{\prime} \mathrm{FeR}+\mathrm{H}
$$

Assuming that there is minimal influence on the other bonds in the complex, the iron-ligand bond enthalpies (relative to iron-hydride) become

$$
\mathrm{D}(\mathrm{Fe}-\mathrm{R})-\mathrm{D}(\mathrm{Fe}-\mathrm{H})=\mathrm{D}(\mathrm{H}-\mathrm{R})-\Delta \mathrm{H}-\mathrm{D}(\mathrm{H}-\mathrm{H})
$$

where $\mathrm{D}$ represents the bond dissociation enthalpy, and the bond enthal pies of $\mathrm{HR}$ and $\mathrm{H}_{2}$ are determined from the literature enthalpies of formations for $H R, R$, and $H .{ }^{35}$ Relative homolytic energies, $D\left(L^{\prime} F e-R\right)-D\left(L^{\prime} F e-\right.$ $\mathrm{H}$ ) estimated from eq 2 are shown in Table 3. A plot of relative $\mathrm{Fe}-\mathrm{R}$ energies against the corresponding $\mathrm{H}-\mathrm{R}$ energies appears in Figure 6 . This plot shows that the $\mathrm{Fe}-\mathrm{R}$ bond strength increases with the corresponding $\mathrm{H}-\mathrm{R}$ BDE. Without considering the hydride and benzyl ligands, the "selectivity slope"29 for the saturated al kyl ligands in this $\Delta D\left(L^{\prime} F e-R\right) / D(H-R)$ plot is 1.8. A much poorer correlation is seen for heterolytic bond energies, so it appears appropriate to describe the $\mathrm{Fe}-\mathrm{C}$ bonds as being primarily covalent.

Figure 6 verifies that the calculated benzylic $\mathrm{Fe}-\mathrm{C}$ bond strength is much greater than what would be predicted from the correlation between the other $\mathrm{Fe}-\mathrm{C}$ and $\mathrm{H}-\mathrm{C}$ bond energies. ${ }^{36}$ It also shows that the $\mathrm{Fe}-\mathrm{H}$ bond is disproportionately strong relative to the $\mathrm{Fe}-\mathrm{C}$ bond, as found by other workers. ${ }^{27}$

$\mathrm{X}$-ray Structures. The molecular structures of $\mathrm{L}^{\mathrm{tBu}}$ FeiBu (3b), LMeF eMe (7a), L MeF eCH ${ }_{2} \mathrm{CH}_{2} \mathrm{CF}_{3}$ (9a), L Me 
Table 4. Selected Bond Distances ( $\AA$ ) and Angles (deg) for Compounds 11-13

\begin{tabular}{|c|c|c|c|c|}
\hline \multicolumn{4}{|c|}{$\mathrm{L}^{\mathrm{MeFeOCHPh}}{ }_{2}$ (11) } & $\mathrm{L}^{\mathrm{MeF}} \mathrm{eN}(\mathrm{C}$ \\
\hline $\begin{array}{l}\mathrm{Fe}-\mathrm{O} \\
\mathrm{N}-\mathrm{Fe}-\mathrm{O} \\
\mathrm{N}-\mathrm{Fe}-\mathrm{N}^{\mathrm{a}} \\
\mathrm{Fe}-\mathrm{O}-\mathrm{C} \\
\mathrm{C}-\mathrm{N}-\mathrm{C}_{\mathrm{Ar}}\end{array}$ & \multicolumn{3}{|c|}{$\begin{array}{l}1.8076(16) \\
142.57(8), 122.84(7) \\
94.48(7) \\
140.42(16) \\
119.72(17), 120.69(15)\end{array}$} & $\begin{array}{l}\mathrm{Fe}-\mathrm{N}_{\text {amide }} \\
\mathrm{N}-\mathrm{Fe}-\mathrm{N}_{\text {amide }} \\
\mathrm{N}-\mathrm{Fe}-\mathrm{N}^{\mathrm{a}} \\
\mathrm{Fe}-\mathrm{N}-\mathrm{C} \\
\mathrm{C}-\mathrm{N}-\mathrm{C}_{\mathrm{Ar}}\end{array}$ \\
\hline \multicolumn{5}{|c|}{ a Diketiminate bite angle. } \\
\hline \multicolumn{5}{|c|}{$\begin{array}{l}\text { Table 5. Selected Structural Data for } \\
\text { Three-Coordinate Alkyl I ron(II) Diketiminates }\end{array}$} \\
\hline & \multicolumn{2}{|c|}{$\mathrm{Fe}-\mathrm{C}$} & \multicolumn{2}{|c|}{$\mathrm{C}-\mathrm{N}-\mathrm{C}_{\mathrm{Ar}}$} \\
\hline $\mathrm{R}$ & $\mathrm{LMe}^{\mathrm{Me}}$ & $\mathrm{L}^{\mathrm{tBu}}$ & $\mathrm{LMe}^{\mathrm{Me}}$ & $\mathrm{L}^{\mathrm{tBu}}$ \\
\hline $\mathrm{Me}$ & $2.003(2)$ & $2.009(3)^{a}$ & $\begin{array}{l}120.99(12) \\
120.76(12)\end{array}$ & $128.56(11)^{a}$ \\
\hline Et & $2.033(3)^{a}$ & & $\begin{array}{l}120.3(2)^{\mathrm{a}} \\
120.7(2)\end{array}$ & \\
\hline iBu & $2.019(6)^{a}$ & $2.055(3)$ & $\begin{array}{l}119.9(2)^{a} \\
120.6(2)\end{array}$ & $\begin{array}{l}126.3(2) \\
128.1(2)\end{array}$ \\
\hline $\mathrm{CH}_{2} \mathrm{tBu}$ & & $2.027(4)^{a}$ & & $\begin{array}{l}126.3(2)^{\mathrm{a}} \\
127.9(2)\end{array}$ \\
\hline$\left(\mathrm{CH}_{2}\right)_{2} \mathrm{CF}_{3}$ & $2.027(6)$ & & $\begin{array}{l}120.6(4) \\
122.7(4)\end{array}$ & \\
\hline iPr & & $2.048(3)^{a}$ & & $\begin{array}{l}125.5(2)^{\mathrm{a}} \\
127.6(2)\end{array}$ \\
\hline $\begin{array}{l}\text { Cy } \\
\text { CHMePh }\end{array}$ & $\begin{array}{l}2.036(2) \\
2.060(2)\end{array}$ & & $\begin{array}{l}120.96(12) \\
119.6(2) \\
120.8(2)\end{array}$ & \\
\hline tBu & & $2.079(4)^{\mathrm{a}}$ & & $\begin{array}{l}127.0(2)^{\mathrm{a}} \\
125.3(2)\end{array}$ \\
\hline
\end{tabular}

a Refs $6,7,8$.

$\mathrm{FeCHMePh}$ (10a), L MeFeOCHPh 2 (11), L MeFeN $\left(\mathrm{CH}_{3}\right)\left(\mathrm{CH}_{2^{-}}\right.$ $\mathrm{Ph}$ ) (12), [L MeF e $\left.\left(\mu-\mathrm{CH}_{2} \mathrm{CN}\right)\right]_{2}$ (13), and LMeFeCy (16a) were determined by single-crystal X-ray diffraction. Sel ected data for compounds $\mathbf{1 1}, \mathbf{1 2}$, and $\mathbf{1 3}$ appear in Table 4. Complete structural parameters for these and all new compounds, along with experimental data used in crystal structure determination, are included in the Supporting Information.

Selected structural data for the three-coordinate iron(II) alkyl complexes appear in Table 5. The iron-carbon bond length increases with the substitution at $\mathrm{C}_{\alpha}$ in both series $L^{\mathrm{Me}} \mathrm{Fe}-\mathrm{R}$ and $\mathrm{L}^{\mathrm{tBu}} \mathrm{Fe}-\mathrm{R}$ with $\mathrm{R}=1^{\circ}<2^{\circ}<3^{\circ}$. Regardless of steric hindrance from the diketiminate ligand, there is free and fast $\mathrm{Fe}-\mathrm{C}$ bond rotation in solution at room temperature in all the alkyl complexes. In one especially clear example, complex 16a has distinct equatorial and axial protons in the solid-state structure (Figure 4f), but fast equilibration of conformers on the ${ }^{1} \mathrm{H}$ NMR time scale yields a single set of cyclohexyl signals at room temperature.

We have reported that addition of $\mathrm{L}^{\mathrm{R}} \mathrm{Li}$ to $\mathrm{FeCl}_{2-}$ $(T H F)_{1.5}$ gives products with different coordination numbers: a four-coordinate iron chl oride complex with $\mathrm{L}^{\mathrm{Me}}, \mathrm{L} \mathrm{MeFe}(\mu-\mathrm{Cl})_{2} \mathrm{Li}(\mathrm{THF})_{2}$ (1a), and a three-coordinate iron chloride complex with $\mathrm{L}^{\mathrm{tBu}}, \mathrm{L}^{\mathrm{tBu}} \mathrm{FeCl}$ (1b). ${ }^{7 \mathrm{~g}}$ The difference in iron coordination number was proposed to arise from the steric bulk of the tert-butyl groups in the

(35) Bartmess, J. E. Negative Ion Energetics Data. In NIST Chemistry WebBook, NIST Standard Reference Database Number 69; Linstrom P. J ., Mallard, W. G., Eds.; National Institute of Standards and Technology: Gaithersburg, MD, 2003 (http://www.nist.gov). The enthalpy values for $\left(\mathrm{PhCH}_{2} \mathrm{CH}_{2}{ }^{\circ}\right)$ and $(\mathrm{PhHMeC} \cdot)$ were not found in the literature, so they were calculated at the B $3 L Y P / 6-31 G(d)$ level of theory with pure (5d and $7 f$ ) $d$ and f functions.

(36) We have not attempted to draw correlations to the homolytic bond energies of substituted benzyl groups, because the bond energies are affected by unusual radical stabilization energies. Pratt, D. A.; Dilabio, G. A.; Mulder, P.; Ingold, A. K. U. Acc. Chem. Res. 2004, 37, 334-340.

\begin{tabular}{lll}
\multicolumn{2}{c}{$\left[\mathrm{LMeFe}^{-}\left(-\mathrm{CH}_{2} \mathrm{CN}\right)\right]_{2}(\mathbf{1 3})$} \\
\hline $1.8715(18)$ & $\mathrm{Fe}-\mathrm{N}_{\mu}$ & $2.0378(15)$ \\
$133.57(7), 133.74(7)$ & $\mathrm{Fe}-\mathrm{C}_{\mu}$ & $2.1409(18)$ \\
$92.66(7)$ & $\mathrm{N}-\mathrm{Fe}-\mathrm{N}^{\mathrm{a}}$ & $93.35(5)$ \\
$122.69(14), 123.54(15)$ & $\mathrm{N}-\mathrm{Fe}-\mathrm{N}_{\mu}$ & $110.40(6), 109.70(6)$ \\
$121.08(16), 121.23(17)$ & $\mathrm{C}-\mathrm{N}-\mathrm{C}_{\mathrm{Ar}}$ & $120.57(14), 121.49(14)$
\end{tabular}

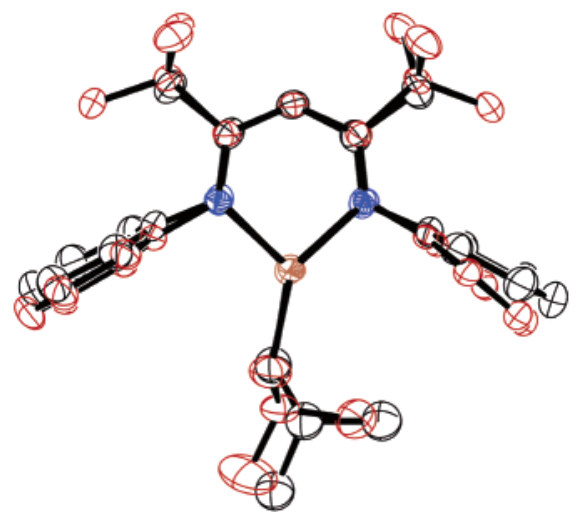

Figure 7. Molecular structures of $L^{R} F$ ei Bu with $L^{\text {tBu }}$ (3b, in red) and $L^{M e}$ (3a), showing the ligand tert-butyl groups pushing the aryl groups. ORTEP diagrams at 50\% probability are viewed along an axis perpendicular to the diketiminate plane. Hydrogen atoms and isopropyl groups are omitted for clarity.

backbone of the larger ligand $\mathrm{L}^{\mathrm{tBu}}$, which pushes the aryl groups toward the open coordination sites on iron. The $\mathrm{C}-\mathrm{N}-\mathrm{C}_{\mathrm{Ar}}$ angle is a quantitative measure of this steric effect: $119(2)^{\circ}$ for $\mathbf{1 a}$ and $128.4(2)^{\circ}$ for $\mathbf{1 b}$. However, there is some ambiguity in the interpretation of the $\mathrm{C}-\mathrm{N}-\mathrm{C}_{\mathrm{Ar}}$ angle because of the difference in coordination number at iron in the two iron chloride complexes. This situation is remedied by the isolation and crystallographic characterization of complexes $\mathbf{3 a}$ and $\mathbf{3 b}$, L $\mathrm{L}^{\mathrm{F}} \mathrm{Fe} \mathrm{iBu}$, and $\mathbf{7 a}$ and $\mathbf{7 b}$, L ${ }^{\mathrm{R}} \mathrm{Fe}-\mathrm{Me}$. Because iron is three-coordinate in each complex, the $\mathrm{C}-\mathrm{N}-\mathrm{C}_{\mathrm{Ar}}$ angle in these compounds is a direct measurement of the steric effect of the backbone substituent. In complexes of $L^{\text {tBu }}$ this angle is consistently pushed $6-8^{\circ}$ toward the open site on iron by the tert-butyl groups, in complexes with the same coordination number (Table 5 , bold numbers). This aryl pushing effect is illustrated in Figure 7 for the isobutyl complexes.

\section{Discussion}

Three-coordinate diketiminate iron(II) alkyl complexes undergo a variety of transformations depending on the steric constraints of the ancillary ligand used, the presence of $\beta$-hydrogens, and the degree of substitution at carbon. These iron(II) alkyl complexes are potentially useful synthetic precursors to low-coordinate inorganic compounds, as exemplified by the syntheses of alkoxide 11, amide 12, and bimetallic 13. This finding is significant because it opens a new synthetic route to alkoxide and amido complexes of iron(II) supported by diketiminato ligands. The alkyl complexes reported here and el sewhere $e^{6,8,37}$ represent the first series of heteroleptic three-coordinate iron(II) hydrocarbyl complexes.

(37) Sciarone, J . J .; Meetsma, A.; Hessen, B.; Teuben, J . H. Chem. Commun. 2002, 1580-1581. 
Compound $\mathbf{1 1}$ is a novel alkoxide complex based on the easily accessible diketiminate ligand LMe.38 Alkoxide complexes with the bulkier ligand $L^{\text {tBu }}$ were recently found to be active initiators for the living polymerization of lactides. ${ }^{38}$ The insertion of imines into metal-hydride bonds giving amides 39 is of interest because of the role that imine insertion plays in catalytic hydrogenation and transfer hydrogenation processes. ${ }^{40}$

We have shown here that the three-coordinate iron alkyl complexes with $\beta$-hydrogen are capable of reacting as an alkyl complex (protonation by amine) or as a hydride complex (protonation by acetonitrile, reduction of ketone to alkoxide, and reduction of imine to amide). It is likely that the different reactivity of the substrates is controlled by the rate of reaction with the alkyl complex. It is well-known that $\mathrm{N}-\mathrm{H}$ protons transfer more quickly than $\mathrm{C}-\mathrm{H}$ protons. ${ }^{41}$ Therefore, it is likely that the iron alkyl is protonated directly in the reaction with amine, but the relatively slow rate of alkyl group protonation by acetonitrile allows $\beta$-hydrogen-containing alkyl complexes time to rearrange. Because the hydride complex is less hindered than the alkyl complex, it preferentially acts as the base in the reaction leading to 13.

We have reported other reactions that proceed directly from the alkyl isomer. For example, CO inserts into three-coordinate $\mathrm{L}^{\mathrm{tBu}} \mathrm{FeR}\left(\mathrm{R}=\mathrm{Me}, \mathrm{CH}_{2} \mathrm{tBu}\right.$, iPr). ${ }^{8} \mathrm{E}$ ven when $\mathrm{R}$ contained $\beta$-hydrogen atoms, these reactions yielded acyl rather than formyl products. Because of the very rapid rate of the carbonylation reactions, we have not been able to distinguish whether the reason is the greater reactivity of carbon ligands toward $\mathrm{CO}$ insertion or because reaction with $\mathrm{CO}$ is faster than $\beta$ - $\mathrm{HE}$.

Alkyl Isomerization Proceeds through $\beta$-Hydride Elimination/I nsertion. There have been few mechanistic investigations on alkyl rearrangements at late transition metals, despite their relevance to useful synthetic processes. Tamaki and Kochi found that the alkyl groups in trans- $\left(\mathrm{PPh}_{3}\right) \mathrm{Me}_{2} \mathrm{AuR}$ complexes $(\mathrm{L}=$ $\mathrm{PPh}_{3}, \mathrm{R}=$ hydrocarbyl) isomerize through $\beta$-hydride elimination. ${ }^{42}$ Reger and co-workers found an analogous mechanism for isomerization of $\mathrm{CpFe}(\mathrm{CO})\left(\mathrm{PPh}_{3}\right)(\text { al kyl })^{43}$ and $\left(\mathrm{R}_{2} \mathrm{NCS}_{2}\right) \mathrm{M}\left(\mathrm{PEt}_{3}\right)(\mathrm{alkyl})(\mathrm{M}=\mathrm{Pd}, \mathrm{Pt}) .{ }^{44}$ Bennett and Maitlis have also implicated $\beta$-hydride elimination/ insertion in studies of alkyl isomerization within coordinated acyl groups, and the available evidence supports the idea that carbonyl deinsertion is rate-liming, fol-

(38) Gibson, V. C.; Marshall, E. L.; Navarro-Llobet, D.; White, A.J. P.; Williams, D. J . J' Chem. Soc., Dalton Trans. 2002, 4321-4322.

(39) (a) Fryzuk, M. D.; Piers, W. E. Organometallics 1990, 9, 986998. (b) Debad, J. D.; Legzdins, P.; Lumb, S. A.; Batchelor, R. J .; Einstein, F. W. B. Organometallics 1995, 14, 2543-2555. (c) Liang, F.; Schmalle, H. W.; Berke, H. Inorg. Chem. 2004, 43, 993-999.

(40) (a) Abdur, R.; Clapham, S. E.; Hadzovic, A.; Harvey, J. N.; Lough, J. A.; Morris, R. H.J . Am Chem. Soc. 2002, 124, 15104-15118. (b) Zhao, I Hesslink, H.; Hartwig, J . F. J . Am Chem. Soc. 2001, 123, 7220-7227. (c) Casey, C. P.; Singer, S. W.; Powell, D. R.; Hayashi, R. K.; Kavana, M. J . Am Chem. Soc. 2001, 123, 1090-1100. (d) Hartwig, J. F. J . Am Chem. Soc. 1996, 118, 7010-7011. Blum, O.; Milstein, D. J . Am. Chem. Soc. 1995, 117, 4582-4594. (e) Lorkovic, I. M.; Duff, R. R., J r.; Wrighton, M. S. J . Am. Chem. Soc. 1995, 117, 3617-3618. (f) Willoughby, C. A.; Buchwald, S. L. J . Am. Chem. Soc. 1994, 116, 11703-11714.

(41) Eigen, M. Angew. Chem., Int. Ed. Engl. 1964, 3, 1-19.

(42) Tamaki, A.; Magennis, S. A.; Kochi, J. K. J . Am. Chem. Soc 1974, 96, 6140-6148.

(43) (a) Reger, D. L.; Culbertson, E. C. J . Am. Chem. Soc. 1976, 98 2789-2794. (b) Reger, D. L.; Culbertson, E. C. I norg. Chem. 1977, 16 3104-3107. (c) Reger, D. L.; McElligot, P. J . J . Organomet. Chem. 1981, 216, C12-C14. lowed by rapid isomerization of the alkyl group. ${ }^{45,46}$ These mechanistic studies of alkyl isomerization were commonly hindered by the necessity of creating an open coordination site prior to the isomerization reaction.

Brookhart and co-workers have studied chain isomerization and transfer in cationic alkyl complexes [(diimine) $\left.\mathrm{M}^{\prime \prime} \mathrm{R}\right]^{+}$of palladium and nickel, in studies relevant to chain running and chain transfer in $\alpha$-olefin polymerizations ${ }^{47}$ The cationic complexes have $\beta$-agostic interactions that stabilize branched over linear alkyl complexes, and addition of an exogenous ligand (ether, $\mathrm{CH}_{3} \mathrm{CN}$, DMSO, or ethylene) gives square planar complexes that do not show $\beta$-agostic interactions and in which linear alkyl complexes are more stable. Isomerization occurs only from the agostic species, ${ }^{47 a, c}$ and interestingly when $\mathrm{R}=\mathrm{Et}$ and $\mathrm{L}^{\prime}$ is labeled ethylene, there is no exchange, ruling out a concerted $\beta$-hydrogen transfer pathway as well as a five-coordinate bis(ol efin) transition state for the isomerization. ${ }^{47 b}$ In contrast, alkene exchange from [(diimine)MR (ethylene) $\left.{ }^{+}\right]\left(R=C_{2}\right.$ alkyl or higher $\neq \mathrm{Me}$ ) is associative and happens through a five-coordinate transition state. ${ }^{47 \mathrm{~b}}$

Complete alkene exchange was recently observed in bis(arylimino)pyridine (BIP) complexes of cobalt(I).48 Treatment of $(\mathrm{BIP}) \mathrm{CoR}(\mathrm{R}=\mathrm{nPr}, \mathrm{nBu})$ complexes with ethylene yields (BIP)CoEt and free al kene (propene or 1-butene). The reaction rate is first order in [Co] and zero order in [ethylene], and it is faster for then-propyl than for then-butyl derivative. Moreover, exchange with propene or ethylene occurs at similar rates. These observations suggested a mechanism involving an alkene hydride intermediate, analogous to mechanism B in Scheme 1.

Our results indicate that alkyl group isomerization and transfer in high-spin iron(II) complexes occur through $\beta$-HE. The highest energy barrier for these reactions is $\beta$-HE from the starting hydrocarbyl complex, as shown from the lack of rate dependence on alkene and by the H/D KIE. This mechanism is consistent with the slower isomerization rates for $\mathrm{L}^{\mathrm{tBu}} \mathrm{com}$ plexes: as a result of the significantly higher steric constraints, a transition state like that shown in Figure 3 , with a higher coordination number at iron, is more difficult to achieve with $\mathrm{L}^{\mathrm{tBu}}$ than for $\mathrm{L}^{\mathrm{Me}}$.

It is likely that the intermediate alkene hydride complex can reversibly dissociate alkene to form a three coordinate iron hydride. We have independently synthesized a relevant hydride compound, $\left[\mathrm{L}^{\mathrm{tBu}} \mathrm{FeH}\right]_{2}$,

(44) (a) Reger, D. L.; Garza, D. G.; Baxter, J . C. Organometallics 1990, 9, 873-874. (b) Reger, D. L.; Garza, D. G.; Lebioda, L. Organometallics 1992, 11, 4285-4292. (c) Reger, D. L.; Ding, Y.; Garza, D. G.; Lebioda, L. J . Organomet. Chem. 1993, 452, 263-270.

(45) (a) Ellis, P. R.; Pearson, J. M.; Haynes, A.; Adams, H.; Bailey, N. A.; Maitlis, P. M. Organometallics 1994, 11, 3213-3226. (b) Haynes, A.; Mann, B. E.; Morris, G. E.; Maitlis, P. M. J . Am. Chem. Soc. 1993, $113,4093-4100$

(46) (a) Bennett, S. L.; Charles, R. J . Am. Chem. Soc. 1972, 94, 666667. (b) Bennett, M. A.; Charles, R.; Mitchell, T. R. B. J. Am. Chem. Soc. 1978, 100, 2737-2743. (c) Bennett, M. A.; J effery, J . C.; Robertson, G. B. Inorg. Chem. 1980, 19, 3763-3767. (d) Bennett, M. A.; Crisp, G. T. Organometallics 1986, 5, 1792-1800.

(47) (a) Tempel, D. J .; J ohnson, L. K.; Huff, R. L.; White, P. S.; Brookhart, M. J . Am. Chem. Soc. 2000, 122, 6686-6700. (b) Shultz, L. H.; Tempel, D. J .; Brookhart, M. J. Am. Chem. Soc. 2001, 123, 11339-11355. (c) Leatherman, M. D.: Svejda, S. A.; J ohnson, L. K.; Brookhart, M. J. Am. Chem. Soc. 2003, 125, 3068-3081. (d) J enkins, J. C.; Brookhart, M. J. Am. Chem. Soc. 2004, 126, 5827-5842.

(48) Gibson, V. C.; Tellmann, K. P.; Humphries, M. J .; Wass, D. F. Chem. Commun. 2002, 2316-2317. 
which dissociates to a monomer at high dilution or high temperature. ${ }^{21}$ Control experiments show that [ $\mathrm{L}^{\mathrm{tBu}}$ $\mathrm{FeH}]_{2}$ reacts with alkenes to form the expected alkyl complexes. Density functional computations (see above) indicate that three-coordinate L'FeH binds ethylene with a modest enthalpy of $7.8 \mathrm{kcal} / \mathrm{mol}$. These data combined support the idea that hydride complexes are the most likely intermediates in alkyl group exchanges between metals. ${ }^{9,49}$

$\boldsymbol{\beta}$-Hydrogen Elimination Is Reversible. Alkene insertion into metal-hydrogen bonds is common among early metals, and this feature is the basis for the useful hydrozirconation reaction. ${ }^{50}$ However, alkyl complexes (particularly of the latetransition metals) with $\beta$-H often decompose in the absence of stabilizing interactions such as geometric constraints. ${ }^{1}$ Hence, $\beta$-hydrogen elimination $(\beta-\mathrm{HE})$ is often regarded as a foe in synthetic chemistry, ${ }^{1,51}$ and generally accepted guidelines for making stable metal al kyls includeavoiding having $\beta-\mathrm{H}$, preventing the $\mathrm{M}-\mathrm{C}-\mathrm{C}-\mathrm{H}$ unit from adopting the coplanar conformation of the transition state for $\beta$ - $\mathrm{HE}$ (cf. Figure 3), or avoiding vacant sites cis to the alkyl ligand. ${ }^{1 \mathrm{C}} \mathrm{N}$ one of these conditions are met in the threecoordinate iron(II) alkyl complexes described here, yet they are stable toward irreversible alkene loss. This stability does not arise from kinetic trapping, because rapid $\beta$-HE clearly occurs at room temperature.

The results of the DFT calculations can be used to calculate the enthal py change for putative $\beta$-HE. Using a thermodynamic cycle, we find that the enthalpies for converson of L'FeR to alkene and L'FeH range between $+13.9 \mathrm{kcal} / \mathrm{mol}(\mathrm{R}=\mathrm{tBu})$ and $+23.0 \mathrm{kcal} / \mathrm{mol}(\mathrm{R}=$ $\mathrm{PhMeCH}$ ), as shown in Table 3. There is a favorable entropy gain with $\beta-\mathrm{HE}$, but for reactions in which 1 particle goes to $2, T \Delta S$ is usually only about $10 \mathrm{kcal} /$ mol,52 not enough to balance the unfavorable $\Delta \mathrm{H}$ contribution. Therefore, theory confirms that enthal pic contributions are responsible for the endothermicity of $\beta$-HE from the three-coordinate iron(II) alkyl complexes.

Other examples of stable late-metal alkyls with $\beta$-H exist in the literature, and some experimental evidence is consistent with reversible olefin insertion occurring in these systems. Among these are Gibson's bis(imino)pyridine cobalt(I) alkyls (see above), which show complete alkyl transfer by a $\beta$ - $\mathrm{H}$ elimination pathway. ${ }^{48}$ Although these 16-electron diamagnetic cobalt complexes reportedly decompose in the absence of an incoming olefin, this was attributed to possible ligand cyclometalation rather than to irreversible olefin loss after $\beta$-HE. Chan has reported rhodium(III) porphyrin complexes that also undergo clean alkyl rearrangement, favoring isomers with electron-withdrawing substituents at the $\alpha$-position. ${ }^{53}$ These rhodium(III) alkyls are

(49) Deng, L.; Margl, P.; Ziegler, T. J . Am. Chem. Soc. 1999, 121, 3998-4004.

(50) (a) Hart, D. W.; Schwartz, J . J . Am. Chem. Soc. 1974, 96, 81138116. (b) Negishi, E.; Takahashi, T. Synthesis 1988, 1-19. (c) Wipf, P.; Xu, W.; Takahashi, H.; J ahn, H.; Coish, P. D. G. PureAppl. Chem. 1997, 69, 639-644. (d) Chirik, P. J .; Day, M. W.; Labinger, J . A.; Bercaw, J. E. J . Am. Chem. Soc. 1999, 121, 10308-10317.

(51) (a) Zhou, J .; Fu, G. C. J . Am. Chem. Soc. 2004, 126, 13401341. (b) Cárdenas, D. J. Angew. Chem., Int. Ed. 2003, 42, 384-387. (c) Cárdenas, D. J . Angew. Chem., Int. Ed. 1999, 38, 3018-3020. (d) Giovannini, R.; Stüdemann, T.; Dussin, G.; Knochel, P. Angew. Chem., Int. Ed. 1998, 37, 2387-2390.

(52) Minas da Piedade, M. E.; Martinho Simões, J . A. J . Organomet. Chem. 1996, 518, 167-180. diamagnetic and have a formal el ectron count of 16 at the metal as well. Kinetics data for these rhodium systems are most consistent with an alkene hydride intermediate (like the one in mechanism B, Scheme 1b).

Diketiminate complexes of other metals have different trends toward $\beta$-hydride elimination. For example, it is possible to isolate the four-coordinate olefin hydride platinum complex $\mathrm{L}^{1} \mathrm{PtH}\left(\eta^{2}-\mathrm{CH}_{2}=\mathrm{CHtBu}\right)\left(\mathrm{L}^{1}=2,4\right.$-bis(2,6-dimethyl-4-tertbutylphenylimino)pent-3-yl). ${ }^{54}$ Meanwhile, Warren has reported a series of four-coordinate nickel alkyls with general formula $\mathrm{L}^{2} \mathrm{NiR}$ (2,4-lutidine) $\left(\mathrm{R}=\mathrm{Me}\right.$, Et, $\mathrm{Pr}, \mathrm{L}^{2}=2,4$-bis(2,4,6-trimethylphenylimino)pent-3-yl). ${ }^{55}$ Despite the isolation of a three-coordinate, formally 11-electron phenyl complex of manganese(II), LMeMnPh,56 the analogous n-butyl compound decomposed, probably through $\beta$-H elimination. Therefore, the three-coordinate geometry imposed by the presence of the diketiminate ligand does not suffice to stabilize the metal-alkyl complexes, neither does it solely explain the reversible ol efin insertion chemistry of the iron(II) alkyls described here.

Relative Stabilities of Alkyl Complexes and Fe-C Bond Energies. Linear saturated alkyl complexes of three-coordinate iron(II) are clearly favored over their branched counterparts. We chose to investigate this trend through DFT calculations on a less sterically hindered model in which the bulky aryl groups are removed. Although larger models gave good quantitative agreement with the observed enthal py changes, we antici pated that the smaller models would generate purely electronic trends in bond energies. This is confirmed by a slope of 1.8 in the plot of relative $\mathrm{Fe}-\mathrm{C}$ bond energies versus the corresponding $\mathrm{H}-\mathrm{C}$ energies for the saturated alkyl ligands (Figure 6). A similar preference for linear alkyl ligands has been observed in analogous plots for compounds of titanium (slope $=$ $1.36),{ }^{29 \mathrm{~d}}$ rhodium (slope $=1.22$ ), ${ }^{29 \mathrm{c}}$ and iridium (slope $=2) .27 \mathrm{c}$

Because terminal alkyl-H bonds are calculated to have higher bond homolytic or dissociation energies (BDEs) than the internal alkyl-H bonds, the large calculated selectivity slopes indicate that the metal prefers the terminal position, even with minimized steric effects. Consistent with this trend, the iron cyclohexyl complexes (containing only secondary positions) are exceptionally good precursors to other alkyl complexes, through loss of cyclohexene. However, benzylic isomers are greatly favored, even when they are secondary and have an accessible primary isomer. Unusual favoritism for benzylic $\mathrm{M}-\mathrm{C}$ bonds has been seen in the literature for $\mathrm{M}-\mathrm{C}$ trends established using $\mathrm{C}-\mathrm{H}$ activation reactions. ${ }^{29 c, d}$ The potential reasons for heightened stability of benzyl complexes are (1) the presence of $\mathrm{C}-\mathrm{H} \cdots \mathrm{M}$ agostic interactions, ${ }^{47,57}$ (2) $\eta^{3}$ coordination, commonly encountered in transition metal benzyl and allyl chemistry, ${ }^{58}$ (3) inductive stabilization

(53) Mak, K. W.; Xue, F.; Mak, T. C. W.; Chan, K. S. J . Chem. Soc., Dalton Trans. 1999, 3333-3334. Mak, K. W.; Chan, K. S. J . Am. Chem Soc. 1998, 120, 9686-9687.

(54) Fekl, U.; Kaminsky, W.; Goldberg, K. I. J . Am. Chem. Soc. 2003, 125, 15286-15287.

(55) (a) Wiencko, H. L.; Kogut, E.; Warren, T. H. Inorg. Chim. Acta 2003, 345, 199-208. (b) Puiu, S. C.; Warren, T. H. Organometallics 2003, 22, 3974-3976

(56) Chai, J.; Zhu, H.; Roesky, H. W.; Magull, J . Organometallics 2004, 23, 1177-1179. 
of partial negative charge on a carbon atom bearing an el ectron-withdrawing substituent, or (4) resonance stabilization of the partial negative charge through charge del ocalization into the aromatic group.

In 10a and the other three-coordinate alkyls we can rule out option (1). None of the alkyl compounds have agostic $\mathrm{C}-\mathrm{H} \cdots$ Fe interactions in the solid state $(\mathrm{H} \cdots \mathrm{Fe}$ $>2.50 \AA$ ). ${ }^{59}$ We can similarly rule out $\eta^{3}$-coordination (2) because the crystal structure of 10a shows simple $\sigma$-coordination of the benzylic carbon, and the ${ }^{1} \mathrm{H}$ NMR shows no evidence that a species other than prim coexists in solution. In addition, the DFT-optimized structures of sterically nonhindered L'FeR models showed no signs of geometric distortion or short distances that would indicate the presence of agostic interactions or aryl $\pi$-coordination. If inductive electron withdrawal (3) were important for the stability of 10a, then the complex $\mathrm{L}^{\mathrm{MeF}} \mathrm{CCH}_{2} \mathrm{CH}_{2} \mathrm{CF}_{3}(\mathbf{9 a})$ would be expected to rearrange (at least partially) to its branched isomer $\mathrm{L}^{\mathrm{MeFeCH}}$ $\left(\mathrm{CH}_{3}\right)\left(\mathrm{CF}_{3}\right)$. However, after heating a solution of $\mathbf{9 a}$, no new species was seen by ${ }^{1} \mathrm{H}$ NMR (see above). Inductive effects operate in other alkyl complexes; for example Reger observed $50 \%$ isomerization of $\left(\mathrm{Me}_{2} \mathrm{NCS}_{2}\right) \mathrm{Pd}$ $\left(\mathrm{PEt}_{3}\right) \mathrm{CH}_{2} \mathrm{CH}_{2} \mathrm{CF}_{3}$ to $\left(\mathrm{Me}_{2} \mathrm{NCS}_{2}\right) \mathrm{Pd}\left(\mathrm{PEt}_{3}\right) \mathrm{CH}\left(\mathrm{CH}_{3}\right)-$ $\left(\mathrm{CF}_{3}\right) .{ }^{44 \mathrm{~b}}$ In Reger's system, replacing the $\mathrm{CF}_{3}$ group with a cyano group led to complete formation of the branched isomer. $44 \mathrm{~b}, 43 \mathrm{c}$

The remaining explanation for the higher stability of 10a is stabilization through resonance stabilization of the partial negative charge (4). .00 This model readily explains the dependence of the equilibrium ratio of phenethyl isomers on the para-substituent (Figure 5) ${ }^{61}$ and the stability of $\mathbf{1 0 a}$ compared to the other alkyl complexes in Figure 6. Interestingly, this resonance stabilization takes place without any geometric distortion of the iron-bound carbon atom toward $\mathrm{sp}^{2}$ hybridization. We note in passing that repulsive $\pi$-interactions between filled metal $d$ orbitals and filled ligand $p$ orbitals $\mathrm{s}^{62}$ are unlikely to be important in alkyl complexes, which lack nonbonding electrons on the ligand.

(57) Agostic $\mathrm{C}-\mathrm{H} \cdots \mathrm{M}$ bonding affects the reactivity of many earlyand late-metal hydrocarbyl complexes: (a) Schmidt, G. F.; Brookhart M. J . Am. Chem. Soc. 1985, 107, 1443-1444. (b) Guo, Z.; Swenson, D. C. Organometallics 1994, 13, 1424. (c) Grubbs, R. H.; Coates, G. W. Acc. Chem. Res. 1996, 29, 85-93. (d) Calhorda, M. J . Chem. Commun. 2000, 801-809. (e) Shultz, L. H.; Brookhart, M. Organometallics 2001 20, 3975-3982. (f) J ensen, V. R.; Thiel, W. Organometallics 2001, 20 4852-4862. (g) Yu, Z.-X.; Houk, K. N. Angew. Chem., Int. Ed. 2003 $42,808-811$.

(58) (a) Mechria, A.; Bavoux, C.; Bouachir, F. J . Organomet. Chem 2003, 677, 53-56. (b) Lee, B. Y.: Bazan, G. C.; Vela, J.: Komon, Z. J. A.; Bu, X. J . Am. Chem. Soc. 2001, 123, 5352-5353. (c) Lesueur, W.; Solari, E.; Floriani, C.; Chiesi-Villa, A.; Rizzoli, C. Inorg. Chem. 1997 36, 3354-3362. (d) Bhandari, G.; Rheingold, A. L.; Theopold, K. H. Chem. Eur. J . 1995, 1, 199-203.

(59) In diimine iron species, agostic interactions are proposed to stabilize the alkyl species that are intermediates in $\alpha$-olefin polymerization:10,49 (a) Griffiths, E. A. H.; Britovsek, G. J . P.; Gibson, V. C.; Gould, I. R. Chem. Commun. 1999, 1333-1334. (b) Khoroshun D. V.; Musaev, D. G.: Vreven, T.; Morokuma, K. Organometallics 2001, 20, 2007-2026.

(60) We cannot rule out the possibility that L MeF eCHMePh (10a) is stabilized somewhat by $\pi$ stacking between the phenyl rings on the hydrocarbyl and diketiminate ligands. In the X-ray structure of 10a, the $\mathrm{C}_{\mathrm{Ar}}-\mathrm{C}_{\mathrm{Ar}}{ }^{\prime}$ contacts are between 3.61 and $4.98 \AA$. Two distances, C32-C44 (3.751 $\AA$ ) and C42-C54 (3.615 $\AA$ ), lie within the 3.3-3.8 range typical of $\pi$ stacking interactions. See: J aniak, C. J . Chem. Soc. Dalton Trans. 2000, 3885-3896.

(61) Other aromatic groups such as pyrrole and pyridine also direct metal binding to the "benzylic" carbon atom: (a) Settambolo, R.; Pucci S.; Bertozzi, S.; Lazzaroni, R. J . Organomet. Chem. 1995, 489, C50C51. (b) Settambolo, R.; Caiazzo, A.; Lazzaroni, R. J . Organomet. Chem. 1996, 506, 337-338.
We recently reported that reaction of L tBuFeNHAr with $\mathrm{PhCCH}\left(\mathrm{pK}_{\mathrm{a}}=23\right)$ or $\mathrm{tBuOH}\left(\mathrm{pK}_{\mathrm{a}}=17\right)$ leads to complete protonation of amide, giving free aniline $\left(\mathrm{pK}_{\mathrm{a}}\right.$

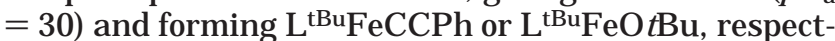
ively. $7 a, 63$ This can be understood as a favoritism for a complex with the more stable anionic ligand (the ligand with the lowest pK $\left.{ }_{a}\right)$. Also, $\mathrm{L}^{\mathrm{MeFeN}}\left(\mathrm{CH}_{3}\right)\left(\mathrm{CH}_{2} \mathrm{Ph}\right)(\mathbf{1 2})$ did not show any sign of rearrangement $\left({ }^{1} \mathrm{H} N M R\right)$ to the carbon-bound isomers $\mathrm{LMeFeCH}_{2} \mathrm{NHCH}_{2} \mathrm{Ph}$ or $\mathrm{LMe}$ $\mathrm{FeCHPh}\left(\mathrm{NHCH}_{3}\right)$ in solution, even after prolonged heating. Ther efore $\mathrm{R}_{2} \mathrm{~N}^{-}$, a harder ligand and a weaker base, forms a more stable complex than $\mathrm{R}_{3} \mathrm{C}^{-}\left(\mathrm{pK}_{a} \mathrm{ca}\right.$. 48). Similar observations were made about the importance of ionic contributions to metal-ligand bonding in nickel $^{29 e}$ and rhenium ${ }^{29 a}$ complexes. Because of resonance stabilization, a benzylic $\mathrm{C}-\mathrm{H}$ bond has a substantially lower $\mathrm{pK}_{a}$ (ca. 41) than that of an alkane ( $\mathrm{pK}_{\mathrm{a}}$ $=48), 63$ and $\mathbf{1 0 a}$ is more stable than the linear phenethyl complex prim (substantially more than would be predicted from the $\mathrm{Fe}-\mathrm{R} / \mathrm{H}-\mathrm{R}$ correlation alone). There fore, one can sum up our thermodynamic findings on alkyl, amido, and al koxo complexes by stating that the $\mathrm{Fe}-\mathrm{X}$ bonds in three-coordinate iron(II) complexes have substantial polarity and can benefit energetically from stabilization of the partial negative charge on the ligand. In support of this idea, recent theoretical studies by Harvey showed that electrostatic effects can explain the bonding energetics in a series of transition metal-alkyl complexes. ${ }^{64}$ In our three-coordinate complexes, this polarity becomes particularly important when hard nitrogen and oxygen ligands replace an alkyl ligand (a stronger base and a less stable anion).

\section{Conclusions and I mplications}

Three-coordinate, paramagnetic iron(II) diketiminate alkyl complexes undergo reversible $\beta$-hydrogen elimination. Our three-coordinate alkyliron(II) complexes add to a growing number of transition metal alkyls containing $\beta$-hydrogen that are stable in the absence of geometric constraints. A common feature in these systems is their ability to undergo reversible $\beta$-HE (olefin deinsertion/reinsertion) reactions. Therefore it appears appropriate to distinguish between a stable metal alkyl and a $\beta$-HE stable metal alkyl. Learning from systems similar to the three-coordinate iron(II) diketiminates and the factors responsible for their unusual stability could lead to strategies for the stabilization of other latemetal alkyls and their incorporation into catalytic pathways. ${ }^{51}$

As a result of the omnipresent, rapid equilibration of the $\beta$ - $\mathrm{H}$-containing alkyls with a small amount of an iron hydride, these alkyl complexes can be considered as synthetic equivalents of a three-coordinate iron(II) hydride complex. We have used this feature to synthesize a variety of low-coordinate iron complexes containing different alkyl, alkoxo, and amido ligands. Experimental and theoretical data show that the driving force for alkyl rearrangement and transfer is enthalpic. Linear alkyls are preferred over their branched isomers, unless resonance stabilization is possible. Resonance

(62) (a) Mayer, J . M. Comments I norg. Chem. 1988, 8, 125-135. (b) Caulton, K. G. New J. Chem. 1994, 18, 25-41.

(63) Values of $\mathrm{pK}_{\mathrm{a}}$ were obtained from ref $31 \mathrm{~b}$

(64) Harvey, J. N. Organometallics 2001, 20, 4887-4895. 
stabilization of the partial negative charge on the ironbound carbon apparently can overpower even severe steric effects.

These metal-carbon bonding preferences are of relevance to the degree of branching in polyolefins made with late-metal catalysts. During the development of homogeneous, late-metal $\alpha$-ol efin polymerization, it was noted that the iron and cobalt catalysts gave linear polymers, ${ }^{10}$ whereas nickel and palladium catalysts were able to produce polymer with a high degree of branching. ${ }^{9,47}$ Brookhart's studies on group 10 metals have shown that "chain walking" (through reversible $\beta$-HE) occurs faster than insertion, ${ }^{47}$ and branching is generally a consequence of the rate of chain walking relative to the rate of ol efin insertion. ${ }^{9}$ The linear nature of the iron- and cobalt-generated polymers would then imply that little chain walking takes place. The studies reported here show that three-coordinate alkyliron(II) complexes show a strong thermodynamic preference for linear alkyl isomers, and this feature may be shared by unsaturated intermediates in the polymerization process. The fast rate of reversible $\beta$-HE in these lowcoordinate iron(II) alkyls suggests that catalytically capable iron complexes could al so undergo substantial chain walking, yet the population of growing chains may be skewed so far toward the thermodynamically favored n-alkyl isomers that essentially all chain growth occurs from them. Of course, the magnitude of this preference is likely to depend on the metal and coligands, as these intimately affect $\mathrm{M}-\mathrm{C}$ bond energies and insertion barriers.

\section{Experimental Section}

General Considerations. Manipulations were performed under a nitrogen atmosphere by standard Schlenk techniques or in an M. Braun Unilab $\mathrm{N}_{2}$-filled glovebox maintained at or below 1 ppm of $\mathrm{O}_{2}$ and $\mathrm{H}_{2} \mathrm{O}$. Glassware was dried at $130{ }^{\circ} \mathrm{C}$ overnight. ${ }^{1} \mathrm{H}$ and ${ }^{19} \mathrm{~F}$ NMR data were recorded on a Bruker Avance $400 \mathrm{MHz}$ spectrometer at the specified temperature. ${ }^{1} \mathrm{H}$ shifts are reported in ppm relative to residual protiated solvent in $\mathrm{C}_{6} \mathrm{D}_{6}(7.13 \mathrm{ppm})$ or $\mathrm{THF}-\mathrm{d}_{8}(3.58 \mathrm{ppm}) .{ }^{19} \mathrm{~F}$ shifts are referenced to $\alpha, \alpha, \alpha$-trifluorotoluene $(\delta-63.73 \mathrm{ppm})$. In the kinetic and equilibrium studies, the NMR probe temperature was calibrated using the ethylene glycol method. 65 Solution magnetic susceptibilities were determined at $294 \mathrm{~K}$ by the Evans method. ${ }^{66}$ Microanalyses were performed at Desert Analytics (Tucson, AZ). Pentane, diethyl ether, tetrahydrofuran (THF), toluene, and acetonitrile were purified by passage through activated alumina and "deoxygenizer" columns from Glass Contour Co. (Laguna Beach, CA). Deuterated benzene and THF were dried over $\mathrm{CaH}_{2}$, then over $\mathrm{Na}$, and then vacuum distilled into a storage container or directly into the NMR tube. tert-Butyl chloride-dg was purchased from Cambridge I sotope Labs and used after filtration through Celite. tert-Butyl-d 9 -magnesium chloride, neo-pentyllithium, and bis(phenethyl)magnesium were prepared by known procedures. ${ }^{67}$ The following compounds were purchased from Aldrich and used as received: Ethylmagnesium chloride ( $2 \mathrm{M}$ in THF), isopropylmagnesium chloride (2 M in diethyl ether), n-butyl-

(65) (a) Ammann, C.; Meier, P.; Merbach, A. E. J . Magn. Reson 1982, 46, 319-321. (b) Kaplan, M. L.; Bovey, F. A.; Cheng, H. N. Anal. Chem. 1975, 47, 1703-1705.

(66) (a) Schubert, E. M. J. Chem. Educ. 1992, 69, 62. (b) Evans, D. F. J . Chem. Soc. 1959, 2003-2005.

(67) (a) Wakefield, B. J . Organomagnesium Methods in Organic Synthesis; Academic Press: London, 1995. (b) Wakefield, B. J . Organolithium Methods; Academic Press: London, 1988. magnesium chloride ( $2 \mathrm{M}$ in diethyl ether), phenethylmagne sium chloride (1 M in THF), tert-butylmagnesium chloride (2 $M$ in diethyl ether), cyclohexylmagnesium chloride (2 $M$ in diethyl ether), ethylene (99.5+\%), propylene (99+\%), and 3,3,3trifluoropropene (99\%). 2-Methyl propene (isobutylene, 99\%) was further purified by vacuum transfer into a Schlenk bomb containing activated molecular sieves and stored overnight prior to use. p-Methyl- and p-methoxystyrene were purchased from Aldrich and were degassed and passed through activated alumina prior to use. p-Dimethylaminostyrene was prepared from $\mathrm{p}$-(dimethylamino)benzal dehyde and triphenylmethylphosphonium bromide as described in the literature. ${ }^{68}$ Compounds $\mathrm{L}^{\mathrm{MeFe}}(u-\mathrm{Cl})_{2} \mathrm{Li}(\mathrm{THF})_{2}(\mathbf{l a}),{ }^{7 \mathrm{~g}}\left[\mathrm{~L}^{\mathrm{MeFeCl}}\right]_{2},{ }^{7 \mathrm{~g}} \mathrm{~L}^{\mathrm{tBu}} \mathrm{FeCl}$ (1b), ${ }^{79}$ L tBuF etBu (2b), ${ }^{6}$ L MeFeiBu (3a), ${ }^{6}$ L MeF eEt (4a), ${ }^{6}$ L tBu $\mathrm{FeCH}_{2} \mathrm{tBu}(\mathbf{8 b}),{ }^{8}$ and $\mathrm{L}^{\mathrm{tBu}} \mathrm{FeMe}(\mathbf{7 b}),{ }^{7 d, e}$ were prepared by known procedures.

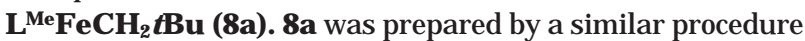
to that reported for $\mathrm{L}^{\mathrm{MeFe}} \mathrm{e}-\mathrm{Bu}^{6}$ and $\mathrm{L}^{\mathrm{tBu}} \mathrm{FeCH}_{2} \mathrm{tBu} .{ }^{8} \mathrm{~A}$ solution of neo-pentyllithium (34.0 mg, $431 \mu \mathrm{mol}$ ) in diethyl ether $(4$ $\mathrm{mL}$ ) was added to a solution of $\mathrm{L}^{\mathrm{MeF}} \mathrm{e}(\mu-\mathrm{Cl})_{2} \mathrm{Li}(\mathrm{THF})_{2}(300 \mathrm{mg}$, $431 \mu \mathrm{mol})$ in diethyl ether $(4 \mathrm{~mL})$. After $4 \mathrm{~h}$ stirring at room temperature, the mixture was filtered through Celite and the solvent pumped down. The bright yellow solid was extracted with pentane $\left(2 \mathrm{~mL}\right.$ ) and cooled to $-38^{\circ} \mathrm{C}$ to give crystals (188 $\mathrm{mg}, 63 \%$ yield). Anal. F ound(calcd): C, 74.57(74.98); H, 8.63(9.62); $N, 5.57(5.14) . \mu_{\text {eff }}\left(C_{6} D_{6}\right)=5.8(3) \mu_{\mathrm{B}} .{ }^{1} \mathrm{H} N M R\left(C_{6} D_{6}, 21\right.$ $\left.{ }^{\circ} \mathrm{C}\right): 130(1, \alpha-\mathrm{CH}), 116\left(9, \mathrm{n}\right.$-pentyl- $\left.\left(\mathrm{CH}_{3}\right)_{3}\right), 72\left(6,\left(\mathrm{CH}_{3}\right)_{2}-\mathrm{L}\right)$, $-12(4, \mathrm{~m}-\mathrm{CH}),-14\left(12, \mathrm{iPr}-\mathrm{CH}_{3}\right),-72(2, \mathrm{p}-\mathrm{CH}),-103(12$, iPr- $\left.\mathrm{CH}_{3}\right),-145$ (4, iPr-CH). Vis (toluene): $467 \mathrm{~nm}$ (720 $\left.\mathrm{M}^{-1} \mathrm{~cm}^{-1}\right), 492 \mathrm{~nm}\left(930 \mathrm{M}^{-1} \mathrm{~cm}^{-1}\right)$. The other alkyl complexes were synthesized through an analogous route; the alkyl donor is listed.

LMeF eCHMePh (10a). 10a was prepared from phenethylmagnesium chl oride; yield 99\%. Anal. Found(calcd): C, 76.90(76.80); $\mathrm{H}, 8.47(8.74) ; \mathrm{N}, 4.89(4.84) . \mu_{\text {eff }}\left(\mathrm{C}_{6} \mathrm{D}_{6}\right)=6.0(3) \mu_{\mathrm{B}} .{ }^{1} \mathrm{H}$ NMR $\left(\mathrm{C}_{6} \mathrm{D}_{6}, 21^{\circ} \mathrm{C}\right): 132(1, \alpha-\mathrm{CH}), 60\left(6,\left(\mathrm{CH}_{3}\right)_{2}-\mathrm{L}\right), 45(2, \mathrm{Ph}-$ o- or $\mathrm{m}-\mathrm{CH}), 31$ (2, Ph-o- or m-CH), -11 (2, L(Ar)-m-CH), -11 (2, L (Ar)-m-CH), -19 (6, iPr-CH $\left.{ }_{3}\right),-19$ (6, iPr-CH $\left.\mathrm{CH}_{3}\right)-57$ (1, $\mathrm{Ph}-\mathrm{p}-\mathrm{CH}),-77$ (2, L (Ar)-p-CH), $-98(2, \mathrm{iPr}-\mathrm{CH}),-119$ (6, i Pr$\left.\mathrm{CH}_{3}\right),-132\left(6, \mathrm{iPr}-\mathrm{CH}_{3}\right),-155(2, \mathrm{iPr}-\mathrm{CH}) .{ }^{69} \mathrm{Vis}$ (toluene): 470 $\mathrm{nm}\left(2040 \mathrm{M}^{-1} \mathrm{~cm}^{-1}\right)$.

LMeFeMe (7a). 7a was prepared from methylmagnesium chloride; yield 90\%. Anal. Found(calcd): C, 73.55(73.76); H, 9.21(9.08); N, 5.78(5.73). $\mu_{\text {eff }}\left(C_{6} D_{6}\right)=6.4(4) \mu_{\mathrm{B}} .{ }^{1} \mathrm{H} N M R\left(C_{6} D_{6}\right.$, $\left.21{ }^{\circ} \mathrm{C}\right): 130(1, \alpha-\mathrm{CH}), 72\left(6,\left(\mathrm{CH}_{3}\right)_{2}-\mathrm{L}\right),-11(4, \mathrm{~m}-\mathrm{CH}),-20$ (12, iPr- $\left.\mathrm{CH}_{3}\right),-74(2, \mathrm{p}-\mathrm{CH}),-119$ (16, iPr-CH 3 , iPr-CH). Vis (pentane): $466 \mathrm{~nm}\left(740 \mathrm{M}^{-1} \mathrm{Cm}^{-1}\right), 491 \mathrm{~nm}\left(1080 \mathrm{M}^{-1} \mathrm{Cm}^{-1}\right)$.

LMeF enPr (14a). 14a was prepared from isopropylmagne sium chloride; yield 81\%. Anal. F ound(calcd): C, 74.11(74.40); $\mathrm{H}, 9.59(9.37) ; \mathrm{N}, 5.15(5.42) . \mu_{\text {eff }}\left(\mathrm{C}_{6} \mathrm{D}_{6}\right)=5.8(3) \mu_{\mathrm{B}} .{ }^{1} \mathrm{H} N M R$ $\left(\mathrm{C}_{6} \mathrm{D}_{6}, 21{ }^{\circ} \mathrm{C}\right): 130(1, \alpha-\mathrm{CH}), 96\left(3, \mathrm{nPr}-\mathrm{CH}_{3}\right), 69\left(6,\left(\mathrm{CH}_{3}\right)_{2^{-}}\right.$ $\mathrm{L}),-12(4, \mathrm{~m}-\mathrm{CH}),-19\left(12, \mathrm{iPr}-\mathrm{CH}_{3}\right),-75(2, \mathrm{p}-\mathrm{CH}),-120$ (16, iPr-CH $\mathrm{CH}_{3}$ i $\left.\mathrm{Pr}-\mathrm{CH}\right)$. Vis (toluene): $463 \mathrm{~nm}\left(760 \mathrm{M}^{-1} \mathrm{~cm}^{-1}\right)$, $490 \mathrm{~nm}\left(930 \mathrm{M}^{-1} \mathrm{~cm}^{-1}\right)$.

LMeFenBu (15a). 15a was prepared from n-butyllithium, yield $97 \%$. Anal. Found(cal cd): C, 74.66(74.70); H, 9.74(9.50); $\mathrm{N}, 5.29(5.28) . \mu_{\text {eff }}\left(\mathrm{C}_{6} \mathrm{D}_{6}\right)=5.9(3) \mu_{\mathrm{B}} .{ }^{1} \mathrm{H} N M R\left(\mathrm{C}_{6} \mathrm{D}_{6}, 21{ }^{\circ} \mathrm{C}\right)$ : $130(1, \alpha-\mathrm{CH}), 91\left(2, \mathrm{nBu}-\gamma-\mathrm{CH}_{2}\right), 69\left(6,\left(\mathrm{CH}_{3}\right)_{2}-\mathrm{L}\right), 65(3, \mathrm{nBu}-$ $\left.\omega-\mathrm{CH}_{3}\right),-12(4, \mathrm{~m}-\mathrm{CH}),-19\left(12, \mathrm{iPr}-\mathrm{CH}_{3}\right),-75(2, \mathrm{p}-\mathrm{CH}),-119$ (16, iPr-CH $\mathrm{CH}_{3}$, $\left.\mathrm{Pr}-\mathrm{CH}\right)$. Vis (toluene): $464 \mathrm{~nm}\left(820 \mathrm{M}^{-1} \mathrm{~cm}^{-1}\right)$, $491 \mathrm{~nm}\left(700 \mathrm{M}^{-1} \mathrm{~cm}^{-1}\right)$.

LMeFeCy (16a). 16a was prepared from cyclohexylmagne sium chl oride; yield $84 \%$. Anal. F ound(calcd): C, 75.05(75.52); $\mathrm{H}, 9.43(9.42) ; \mathrm{N}, 5.03(5.03)$. $\mu_{\text {eff }}\left(\mathrm{C}_{6} \mathrm{D}_{6}\right)=5.7(3) \mu_{\mathrm{B}}$. ${ }^{1} \mathrm{H}$ NMR $\left(\mathrm{C}_{6} \mathrm{D}_{6}, 21^{\circ} \mathrm{C}\right): 134(1, \alpha-\mathrm{CH}), 115\left(4, \mathrm{Cy}-\gamma-\mathrm{CH}_{2}\right), 64\left(6,\left(\mathrm{CH}_{3}\right)_{2^{-}}\right.$ L), $-13(4, \mathrm{~m}-\mathrm{CH}),-18\left(12, \mathrm{iPr}-\mathrm{CH}_{3}\right),-77(2, \mathrm{p}-\mathrm{CH}),-120$

(68) Iida, T.; I taya, T. Tetrahedron 1993, 49, 10511-10530.

(69) Although the stereogenic $C_{\alpha}$ makes all proton groups chemically and magnetically inequivalent, some signals are unresolved because of peak broadness caused by the paramagnetic iron center. 
(12, i Pr- $\left.\mathrm{CH}_{3}\right),-130$ (4, iPr-CH). Vis (toluene): $461 \mathrm{~nm}$ (1280 $\left.\mathrm{M}^{-1} \mathrm{~cm}^{-1}\right), 486 \mathrm{~nm}\left(1080 \mathrm{M}^{-1} \mathrm{~cm}^{-1}\right)$.

dy-LMeFei Bu (d $\mathbf{d}$-3a). d d9-tert-Butylmagnesium chloride (735 $\mu \mathrm{mol}$, prepared in situ) was filtered into a diethyl ether solution containing la (460 mg, $662 \mu \mathrm{mol})$. After $2 \mathrm{~h}$ stirring at room temperature, the white precipitate was allowed to settle and the solution was filtered through Celite. Concentration under vacuum afforded a solid that was extracted with pentane ( $4 \mathrm{~mL})$, filtered, concentrated (to $2 \mathrm{~mL}$ ), and cooled to $-38{ }^{\circ} \mathrm{C}$, affording crystals: $211 \mathrm{mg}(59 \%) .{ }^{1} \mathrm{H}$ NMR $\left(\mathrm{C}_{6} \mathrm{D}_{6}\right.$, $\left.21{ }^{\circ} \mathrm{C}\right): 130(1, \alpha-\mathrm{CH}), 70\left(6,\left(\mathrm{CH}_{3}\right)_{2}-\mathrm{L}\right),-12(4, \mathrm{~m}-\mathrm{CH}),-18$ $\left(12, \mathrm{iPr}-\mathrm{CH}_{3}\right),-74(2, \mathrm{p}-\mathrm{CH}),-114\left(12, \mathrm{iPr}-\mathrm{CH}_{3}\right),-132$ (4, iPr$\mathrm{CH})$.

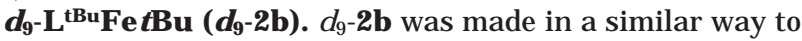
$\mathrm{d}_{9}$-LMeF ei Bu from d $\mathrm{d}_{9}$-tert-butylmagnesium chloride (368 $\mu \mathrm{mol}$, prepared in situ) and $\mathbf{1 b}$ (175 mg, $294 \mu \mathrm{mol}): 137 \mathrm{mg}(77 \%)$. ${ }^{1} \mathrm{H}$ NMR $\left(\mathrm{C}_{6} \mathrm{D}_{6}, 21{ }^{\circ} \mathrm{C}\right): 130(1, \alpha-\mathrm{CH}), 46\left(18, \mathrm{C}\left(\mathrm{CH}_{3}\right)_{3}-\mathrm{L}\right),-7$ $(4, \mathrm{~m}-\mathrm{CH}),-26\left(12, \mathrm{iPr}-\mathrm{CH}_{3}\right),-102$ (6, i $\left.\mathrm{Pr}-\mathrm{CH}, \mathrm{p}-\mathrm{CH}\right),-150$ (12, iPr- $-\mathrm{CH}_{3}$ ).

${ }^{1} \mathbf{H}$ NMR Observation of $\mathrm{L}$ MeF eCH ${ }_{2} \mathbf{C H}_{2} \mathbf{P h}$ (prim). Bis(phenethyl)magnesium (22 mg, $99 \mu \mathrm{mol})$ and $\left[\mathrm{L}^{\mathrm{MeFeCl}}\right]_{2}(92$ $\mathrm{mg}, 90 \mu \mathrm{mol})$ were mixed in $\mathrm{C}_{6} \mathrm{D}_{6}(2 \mathrm{~mL})$ inside a vial. The vial was stirred at room temperature for $10 \mathrm{~min}$, and then the mixture was allowed to settle for $5 \mathrm{~min}$. The soluble fraction was decanted and filtered and the resulting yellow solution monitored by ${ }^{1} \mathrm{H} N \mathrm{NR}$ at this point. The primary complex was observed initially, and upon heating to $60{ }^{\circ} \mathrm{C}$, complete conversion to the equilibrium mixture was achieved within 2 h. Spectral assignment for $\mathrm{L}^{\mathrm{MeF}} \mathrm{eCH} \mathrm{CH}_{2} \mathrm{CH}_{2} \mathrm{Ph}$ (prim): ${ }^{1} \mathrm{H} N M R$ $\left(\mathrm{C}_{6} \mathrm{D}_{6}, 21^{\circ} \mathrm{C}\right)$ : $128(1, \alpha-\mathrm{CH}), 92(2,(\mathrm{Ph})-\mathrm{o}-$ or $\mathrm{m}-\mathrm{CH}), 67$ (6, $\left.\left(\mathrm{CH}_{3}\right)_{2}-\mathrm{L}\right), 40$ (2, (Ph)-o- or m-CH), 31 (1, (Ph)-p-CH), -11 (4, $\mathrm{L}(\mathrm{Ar})-\mathrm{m}-\mathrm{CH}),-20$ (12, iPr-CH $)_{3},-76$ (2, L(Ar)-p-CH), -120 (16, iPr-CH and iPr-CH).

Substituted Phenethyl Complexes. Synthesis. A resealable J . Young N MR tube was loaded with L MeFeCy (12 mg, $25 \mu \mathrm{mol})$, the desired styrene (1.02 equiv), and $\mathrm{C}_{6} \mathrm{D}_{6}(0.4 \mathrm{~mL})$. The tube was agitated for a day at room temperature or warmed to $50{ }^{\circ} \mathrm{C}$ for $3 \mathrm{~h}$, achieving in both cases clean conversion to a mixture of benzylic/primary complexes.

LMeFeCHMe(p-Me- $\left.\mathrm{C}_{6} \mathrm{H}_{5}\right)$. ${ }^{1} \mathrm{H}$ NMR $\left(\mathrm{C}_{6} \mathrm{D}_{6}, 21{ }^{\circ} \mathrm{C}\right): 116(1$, $\alpha-\mathrm{CH}), 86\left(3,(\mathrm{Ph})-\mathrm{p}-\mathrm{CH}_{3}\right), 62\left(6,\left(\mathrm{CH}_{3}\right)_{2}-\mathrm{L}\right), 45$ (2, (Ph)-o- or $\mathrm{m}-\mathrm{CH}), 30$ (2, (Ph)-o- or $\mathrm{m}-\mathrm{CH}),-12$ (doublet, $2 \times 2$, L (Ar)$\mathrm{m}-\mathrm{CH}),-20\left(6 \mathrm{H}, \mathrm{iPr}-\mathrm{CH}_{3}\right),-20\left(6 \mathrm{H}, \mathrm{iPr}-\mathrm{CH}_{3}\right),-78(2, \mathrm{~L}(\mathrm{Ar})-$ p-CH), -102 (2, iPr-CH), $-122\left(6, \mathrm{iPr}-\mathrm{CH}_{3}\right),-111\left(6, \mathrm{iPr}-\mathrm{CH}_{3}\right)$ $-160(2, \mathrm{iPr}-\mathrm{CH}){ }^{69}$

LMeFeCHMe(p-MeO-C $\left.{ }_{6} \mathrm{H}_{5}\right) .{ }^{1} \mathrm{H}$ NMR $\left(\mathrm{C}_{6} \mathrm{D}_{6}, 21^{\circ} \mathrm{C}\right): 116$ (1, $\alpha-\mathrm{CH}), 62\left(6,\left(\mathrm{CH}_{3}\right)_{2}-\mathrm{L}\right), 44$ (2, (Ph)-o- or $\left.\mathrm{m}-\mathrm{CH}\right), 25$ (2, (Ph)o- or $\mathrm{m}-\mathrm{CH}$ ), 17 (3, (Ph)-p-OCH $\mathrm{OCH}_{3},-11$ (doublet, $2 \times 2$, L (Ar)$\mathrm{m}-\mathrm{CH}$ ),-19 (doublet, $2 \times 6 \mathrm{H}$, iPr- $\left.\mathrm{CH}_{3}\right),-78(2, \mathrm{~L}(\mathrm{Ar})-\mathrm{p}-\mathrm{CH})$, -100 (2, iPr-CH), $-122\left(6, \mathrm{i} P r-\mathrm{CH}_{3}\right),-112\left(6, \mathrm{iPr}-\mathrm{CH}_{3}\right),-135$ (2, iPr-CH). ${ }^{69}$

LMeFeCHMe(p-NMe $\left.-\mathrm{C}_{6} \mathrm{H}_{5}\right) \cdot{ }^{1} \mathrm{H}$ NMR $\left(\mathrm{C}_{6} \mathrm{D}_{6}, 2{ }^{\circ} \mathrm{C}\right): 116$ (1, $\alpha-\mathrm{CH}), 59\left(6,\left(\mathrm{CH}_{3}\right)_{2}-\mathrm{L}\right), 43$ (2, (Ph)-o- or $\left.\mathrm{m}-\mathrm{CH}\right), 20$ (2, (Ph)o- or $\mathrm{m}-\mathrm{CH}), 16$ (6, (Ph)-p-N $\left.\left(\mathrm{CH}_{3}\right)_{2}\right),-11$ (2, L(Ar)-m-CH), -11 (2, L (Ar)-m-CH), $-18\left(6, \mathrm{iPr}-\mathrm{CH}_{3}\right),-18\left(6, \mathrm{iPr}-\mathrm{CH}_{3}\right),-76(2$, $\mathrm{L}(\mathrm{Ar})-\mathrm{p}-\mathrm{CH}),-105$ (2, iPr-CH),-119 (6, iPr-CH $\left.{ }_{3}\right),-129$ (6, iPr- $\left.\mathrm{CH}_{3}\right),-160(2, \mathrm{iPr}-\mathrm{CH}) .69$

Equilibrium Studies. Internal-to-terminal ratios $\left(K_{\text {eq }}\right)$ were obtained by ${ }^{1} \mathrm{H}$ NMR at different temperatures ${ }^{65}$ for each substituted pair. Total iron concentration was $63 \mathrm{mM}$ in each case. Integrations were compared against an internal standard as done for the kinetics experiments. No systematic variation of normalized total iron concentration ( $\pm 2 \%$ ) was observed during the course of the experiments. Error bars for integrati ons obtained from N M R spectra were cal culated assuming a confidence level of $1 \% .{ }^{24}$ Error bars for thermodynamic parameters were calculated on the basis of the maximum and miminum deviations of the van't Hoff plot through the error limits of the individual data points.

$\mathbf{L}^{\text {tBu}} \mathbf{F}$ ei Bu (3b). 3b was prepared from thermal isomerization of L ${ }^{\text {tBuF }}$ etBu (2b) (300 mg, $\left.488 \mu \mathrm{mol}\right)$ in toluene $(4 \mathrm{~mL})$ at
$80{ }^{\circ} \mathrm{C}$ overnight. The solvent was pumped down, and the remaining bright orange solid was extracted with pentane (3 $\mathrm{mL})$, filtered through Celite, and cooled to $-38{ }^{\circ} \mathrm{C}$ to give crystals (246 mg, 81\%). Anal. Found(calcd): C, 76.63(76.19); $\mathrm{H}, 10.20(10.17) ; \mathrm{N}, 4.65(4.56) . \mu_{\text {eff }}\left(\mathrm{C}_{6} \mathrm{D}_{6}\right)=5.7(3) \mu_{\mathrm{B}} .{ }^{1} \mathrm{H} \mathrm{NMR}$ $\left(\mathrm{C}_{6} \mathrm{D}_{6}, 21{ }^{\circ} \mathrm{C}\right): 110(1, \alpha-\mathrm{CH}), 121\left(18, \mathrm{C}\left(\mathrm{CH}_{3}\right)_{3}-\mathrm{L}\right),-5(4$ $\mathrm{m}-\mathrm{CH}),-28\left(12, \mathrm{iPr}-\mathrm{CH}_{3}\right),-107$ (6, iPr-CH, p-CH), $-118(12$, iPr- $\left.\mathrm{CH}_{3}\right)$. Vis (toluene): $521 \mathrm{~nm}\left(660 \mathrm{M}^{-1} \mathrm{~cm}^{-1}\right)$.

Syntheses of Alkyl, Alkoxide, and Amido Complexes via Alkyl Transfer Reactions: $\mathrm{L}^{\mathrm{MeFeC}} \mathrm{CH}_{2} \mathrm{CH}_{2} \mathrm{CF}_{3}$ (9a). A Schlenk flask was loaded with L MeF e-iBu (200 mg, $377 \mu \mathrm{mol})$, toluene (4 mL), and 3,3,3-trifluoropropene (condensed from a calibrated volume bulb: $380 \mu \mathrm{mol})$, then heated to $80{ }^{\circ} \mathrm{C}$ overnight. After pumping down the solvent, the remaining solid was extracted with pentane $(3 \mathrm{~mL})$, filtered through Celite, and cooled to $-38{ }^{\circ} \mathrm{C}$ to give yellow crystals (174 mg, $80 \%$ yield). Anal. Found(calcd): C, 66.89(67.36); H, 8.36(7.95); $\mathrm{N}, 5.11(4.91) . \mu_{\mathrm{eff}}=5.6(3) \mu_{\mathrm{B}} .{ }^{1} \mathrm{H}$ NMR $\left(\mathrm{C}_{6} \mathrm{D}_{6}, 21{ }^{\circ} \mathrm{C}\right): 125(1$, $\alpha-\mathrm{CH}), 66\left(6,\left(\mathrm{CH}_{3}\right)_{2}-\mathrm{L}\right),-9(4, \mathrm{~m}-\mathrm{CH}),-20\left(12, \mathrm{iPr}-\mathrm{CH}_{3}\right),-79$ $(2, \mathrm{p}-\mathrm{CH}),-121$ (16, iPr- $\left.\mathrm{CH}_{3}, \mathrm{iPr}-\mathrm{CH}\right) .{ }^{19} \mathrm{~F} N M R\left(\mathrm{C}_{6} \mathrm{D}_{6}, 21\right.$ $\left.{ }^{\circ} \mathrm{C}\right): 128\left(\mathrm{CF}_{3}\right) . \mathrm{Vis}$ (toluene): $460 \mathrm{~nm}\left(710 \mathrm{M}^{-1} \mathrm{~cm}^{-1}\right), 490 \mathrm{~nm}$ $\left(921 \mathrm{M}^{-1} \mathrm{~cm}^{-1}\right)$. Heating a solution of $9 a$ at $80^{\circ} \mathrm{C}$ for extended periods of time did not result in formation of new compounds. Formation of the secondary isomer $\mathrm{L}^{\mathrm{Me}} \mathrm{FeCH}\left(\mathrm{CH}_{3}\right)\left(\mathrm{CF}_{3}\right)$ would have resulted in a loss of symmetry of the ${ }^{1} \mathrm{HNMR}$ spectrum as seen for $\mathrm{L}^{\mathrm{MeFeCH}}\left(\mathrm{CH}_{3}\right)(\mathrm{Ph})$ (10a) (see above).

$\mathbf{L}^{\mathrm{Me}} \mathbf{F e O C H P h} \mathbf{2}$ (11). 11 was synthesized similarly, from $\mathrm{L}^{\mathrm{MeF}}$ eiBu ( $238 \mathrm{mg}, 445 \mu \mathrm{mol}$ ) and dry benzophenone ( $81.2 \mathrm{mg}$ $445 \mu \mathrm{mol}$ ); green crystals ( $262 \mathrm{mg}, 89 \%$ yield). Anal. Found(calcd): C, 76.58(76.81); H, 8.00(7.98); N , 4.19(4.27). $\mu_{\text {eff }}=5.1$ (3) $\mu_{\mathrm{B}} .{ }^{1} \mathrm{H} N \mathrm{NMR}\left(\mathrm{C}_{6} \mathrm{D}_{6}, 21{ }^{\circ} \mathrm{C}\right)$ : $110(1, \alpha-\mathrm{CH}), 110$ (4, (OR)-o$\mathrm{CH}), 52\left(6,\left(\mathrm{CH}_{3}\right)_{2}-\mathrm{L}\right), 29$ (4, (OR)-m-CH), 21 (2, (OR)-p-CH), -16 (4, L (Ar)-m-CH), -23 (12, iPr-CH $\mathrm{CH}_{3},-75$ (2, L (Ar)-p-CH), -119 (16, iPr-CH $\mathrm{CH}_{3}$ iPr-CH). Vis (toluene): $492 \mathrm{~nm}\left(540 \mathrm{M}^{-1}\right.$ $\left.\mathrm{cm}^{-1}\right)$.

LMeF eN $\left(\mathbf{C H}_{3}\right) \mathbf{C H}_{2} \mathbf{P h}$ (12). 12 was synthesized from $\mathrm{L}^{\mathrm{Me}}$ FeiBu (400 mg, $754 \mu \mathrm{mol}$ ) and N-benzyl idenemethylamine (98 $\mu \mathrm{L}, 754 \mu \mathrm{mol}$ ); orange crystals (317 $\mathrm{mg}, 72 \%$ yield). Anal. Found(calcd): C, 74.42(74.98); H, 8.80(8.50); N, 6.80(7.09). $\mu_{\text {eff }}$ $=5.6(3) \mu_{\mathrm{B}} .{ }^{1} \mathrm{H}$ NMR $\left(\mathrm{C}_{6} \mathrm{D}_{6}, 21^{\circ} \mathrm{C}\right): 116(1, \alpha-\mathrm{CH}), 87(2,(\mathrm{NR})-$ o- $\mathrm{CH}), 35$ (2, (NR)-m-CH), 27 (1, (NR)-p-CH), 7 (6, $\left.\left(\mathrm{CH}_{3}\right)_{2}-\mathrm{L}\right)$, $-13(4, \mathrm{~m}-\mathrm{CH}),-20\left(12, \mathrm{PPr}-\mathrm{CH}_{3}\right),-81(2, \mathrm{p}-\mathrm{CH}),-119(16$, iPr-CH ${ }_{3}$, iPr-CH). Vis (toluene): $373 \mathrm{~nm}\left(6200 \mathrm{M}^{-1} \mathrm{~cm}^{-1}\right), 422$ $\mathrm{nm}\left(3400 \mathrm{M}^{-1} \mathrm{~cm}^{-1}\right), 491 \mathrm{~nm}\left(760 \mathrm{M}^{-1} \mathrm{~cm}^{-1}\right)$.

[LMeFe $\left.\left(\mu-\mathrm{CH}_{2} \mathbf{C N}\right)\right]_{2}$ (13). A Schlenk flask was loaded with L MeFei Bu (31a) $(200 \mathrm{mg}, 387 \mu \mathrm{mol})$, acetonitrile $(16.0 \mathrm{mg}, 387$ $u \mathrm{~mol})$, and pentane $(4 \mathrm{~mL})$ and heated to $60^{\circ} \mathrm{C}$ overnight with constant stirring. The solution was filtered through Celite, concentrated $(2 \mathrm{~mL})$, and cooled to $-38{ }^{\circ} \mathrm{C}$ to give yellow crystals (125 mg, 73\% yield). Anal. Found(calcd): C, 71.96(72.50); $\mathrm{H}, 8.66(8.48) ; \mathrm{N}, 8.88(8.44)$. $\mu_{\text {eff }}\left(\mathrm{C}_{6} \mathrm{D}_{6}\right.$, per dimer $)=$ $6.5(3) \mu_{\mathrm{B}} .{ }^{1} \mathrm{H} N M R\left(\mathrm{C}_{6} \mathrm{D}_{6}, 21^{\circ} \mathrm{C}\right): 23,20,0.1,-6.0,-29,-41$ -73; spectrum is complicated and difficult to assign, possibly indicating impurities or a slow dynamic process in solution. Vis (toluene): $435 \mathrm{~nm}\left(4100 \mathrm{M}^{-1} \mathrm{~cm}^{-1}\right)$.

Kinetics Studies. A resealable NMR tube was loaded with a solution of $\mathbf{3} \mathbf{a}, \mathrm{d}_{9}-\mathbf{3} \mathbf{a}, \mathbf{2} \mathbf{b}$, or $\mathrm{d}_{9}-\mathbf{2} \mathbf{b}$ (ca. $0.04 \mathrm{M}$ in $\mathrm{C}_{6} \mathrm{D}_{6}$ ). The NMR spectrometer probe was equilibrated at the given temperature, ${ }^{65}$ and ${ }^{1} \mathrm{H}$ NMR spectra were collected periodically. A capillary with a solution of complex $\mathrm{L}^{\text {tBuF }} \mathrm{Fel}$ in $\mathrm{C}_{6} \mathrm{D}_{6}$ was used as an internal standard. ${ }^{70}$ No significant variation in the total iron concentration versus internal standard was observed over time, and no intermediates were detected. A plot of starting material concentration (y) against reaction time (t) was analyzed with KaleidaGraph v. 3.51. This curve was used to find the best fit to the general first-order integrated kinetic equation $y=M_{1}+M_{2}[\exp (-k t)]$, where $M_{1}$ and $M_{2}$ are constants and $\mathrm{k}$ is the first-order rate constant. ${ }^{71}$ This fitting

(70) L ${ }^{\text {tBuFeCl }}$ was used as an integration standard because its relaxation time is similar to the compounds studied here. 
procedure also yielded error bars as calculated from the standard deviations from the individual data points. In the experiments with volatile alkenes, the solution was frozen in a liquid nitrogen bath, its headspace was evacuated, and then a known amount of gaseous alkene was condensed in from a cal ibrated volume bulb at $294 \mathrm{~K}$. Alkene was identified in the volatile materials extracted from the reaction mixture by ${ }^{1} \mathrm{H}$ NMR and GC/MS.

Alkyl Crossover Experiments. A solution of two complexes (ca. $40 \mathrm{mM}$ each) in $0.40 \mathrm{~mL}$ of $\mathrm{C}_{6} \mathrm{D}_{6}$ was heated to 60 , 80 , and $100{ }^{\circ} \mathrm{C}$ in an oil bath for overnight periods and monitored by ${ }^{1} \mathrm{H}$ NMR spectroscopy. Concentrations were calculated from integration of resonances for alkyl- $\beta-\mathrm{CH}$ protons (120 to $80 \mathrm{ppm}$ ), diketiminate backbone methyl (80 to $50 \mathrm{ppm}$ ), and tBu (30 to $50 \mathrm{ppm}$ ) groups and $\mathrm{p}-\mathrm{CH}$ ( -60 to $-75 \mathrm{ppm}$ ) from aryl rings in $\mathrm{L} \mathrm{Me}$.

Computational Methods. Calculations on L'FeR model systems $\left(\mathrm{L}^{\prime}=\mathrm{C}_{3} \mathrm{~N}_{2} \mathrm{H}_{5}{ }^{-}\right.$) employed the Gaussian98 quantum chemistry program package. ${ }^{72}$ The systems were model ed with the B3L YP hybrid density functional ${ }^{73}$ and the 6-31G(d) allelectron basis set, which includes an f function on iron. For simple L'FeR complexes all plausible conformations were manually generated and evaluated at the B3LYP/6-31G(d) level of theory, and the lowest energy conformations were used. Geometry optimizations were performed on all atoms without constraint of symmetry. Frequencies were calculated to confirm all species as minima (zero imaginary frequencies) or transition states (one imaginary frequency). All calculations were performed on the quintet state of L'FeR, which was indicated in previous experiments and calculations to be the ground state. ${ }^{7 b}$ The unrestricted Kohn-Sham formalism was employed. Calculated energetics include enthalpic and zeropoint energies determined at 1 atm and $298.13 \mathrm{~K}$ using B3LYP/6-31G(d) analytical frequencies.

The Titan ${ }^{74}$ program was used to build LMeFeR complexes. The molecular structures were minimized using the $\mathrm{MOE}^{75}$ package and the MMFF ${ }^{76}$ force field. The minimized structure was subjected to conformational analysis using the Hybrid

(71) Espenson, J . H. Chemical Kinetics and Reaction Mechanisms, 2nd ed.; McGraw-Hill: New York, 1995.

(72) Frisch, M. J .; Trucks, G. W.; Schlegel, H. B.; Scuseria, G. E . Robb, M. A.; Cheeseman, J . R.; Zakrzewski, V. G.; Montgomery, J . A.; Stratmann, R. E.; Burant, J . C.; Dapprich, S.; Millam, J. M.; Daniels, A. D.; Kudin, K. N.; Strain, M. C.; Farkas, O.; Tomasi, J .; Barone, V.; Cossi, M.; Cammi, R.; Mennucci, B.; Pomelli, C.; Adamo, C.; Clifford, S.; Ochterski, J .; Petersson, G. A.; Ayala, P. Y.; Cui, Q.; Morokuma K.; Malick, D. K.; Rabuck, A. D.; Raghavachari, K.; Foresman, J. B.; Cioslowski, J .; Ortiz, J . V.; Stefanov, B. B.; Liu, G.; Liashenko, A.; Piskorz, P.; Komaromi, I.; Gomperts, R.; Martin, R. L.; Fox, D. J .; Keith T.; Al-Laham, M. A.; Peng, C. Y.; Nanayakkara, A.; Gonzalez, C.; Challacombe, M.; Gill, P. M. W.; J ohnson B. G.; Chen, W.; Wong, M. W.; Andres, J. L.; Head-Gordon, M.; Replogle, E. S.; Pople, J. A. Gaussian 98 (Revision A.1); Gaussian Inc.: Pittsburgh, PA, 2001.

(73) Becke, A. D. J . Chem. Phys. 1993, 98, 5648-5652.

(74) Titan; Wavefunction, Inc., Schrödinger, Inc., 1999.

(75) MOE 2002.03; Chemical Computing Group Inc., http://www.chemcomp.com/.
Monte $\mathrm{Carlo}^{75}$ technique to determine the lowest energy structure. After an initial equilibration of 1000 time steps, the molecular dynamics (MD) calculations were performed at 300 $\mathrm{K}$ for 200000 iteration steps. The MD time step was 0.005 ps. The lowest energy conformer was used as a starting point for B3LYP/6-31G(d) geometry optimization of LMeF eR.

$\mathrm{X}$-ray Structures. Crystalline samples were grown in the glovebox from pentane or ether solutions at $-38{ }^{\circ} \mathrm{C}$. Each sample was rapidly mounted under Paratone-8277 onto a glass fiber and immediately placed in a cold nitrogen stream at -80 ${ }^{\circ} \mathrm{C}$ on the X-ray diffractometer. X-ray intensity data were collected on a standard Bruker-axs SMART CCD Area Detector System equipped with a normal focus molybdenum-target X-ray tube operated at $2.0 \mathrm{~kW}(50 \mathrm{kV}, 40 \mathrm{~mA})$. A total of 1121 frames of data (2424 for $\mathrm{L}^{\mathrm{MeFeCH}} \mathrm{CH}_{2} \mathrm{CH}_{2} \mathrm{CF}_{3}$ and $\mathrm{L}^{\mathrm{MeN}}$ (Me) $\left(\mathrm{CH}_{2^{-}}\right.$ $\mathrm{Ph})$ ) were collected using a narrow frame method with scan widths of $0.3^{\circ}$ in $\omega$. Frames were integrated to a maximum $2 \theta$ angle of $56.6^{\circ}$ with SAINT. The final unit cell parameters (at $-80{ }^{\circ} \mathrm{C}$ ) were determined from the least-squares refinement of three-dimensional centroids of $>4000$ reflections for each crystal. Data were corrected for absorption with the SADABS ${ }^{77}$ program.

The space groups were assigned using XPREP, and the structures were solved by direct methods and refined employing full-matrix least-squares on $\mathrm{F}^{2}$ (Bruker-axs, SHELXTL$\mathrm{NT}, 78$ version 5.10). All non-H atoms were refined with anisotropic thermal parameters. Hydrogen atoms were included in idealized positions. The structures refined to goodness-of-fit values and final residuals found in the Supporting Information.

Acknowledgment. This work was sponsored by the National Science Foundation (CHE-0112658 to P.L.H. and CHE-0309811 to T.R.C.) and the Department of Energy (F G02-97ER 14811 to T.R.C.). Wealso thank the A. P. Sloan F oundation (Research Fellowship to P.L.H.) and the University of Rochester (Hooker Fellowship to J.V.). T.R.C. acknowledges the Chemical Computing Group for supplying the MOE program. We are indebted to Prof. Bill J ones and Prof. J oe Dinnocenzo for insightful comments, and Sandip Sur for assistance with variable-temperature NMR.

Supporting Information Available: Additional kinetics and thermodynamics data, calculated geometries, and CIF files. This material is available free of charge via the Internet at http://pubs.acs.org.

\section{OM049415+}

(76) Halgren, T. A. J . Comput. Chem. 1995, 17, 490-519.

(77) The SADABS program is based on the method of Blessing; see: Blessing, R. H. Acta Crystallogr. A 1995, 51, 33-38.

(78) SHELXTL NT: Structure Analysis Program, version 5.10; Bruker-AXS: Madison, WI, 1995. 